\title{
Challenges and Lessons Learned From Resurrecting a Legacy Research Flight Controller
}

\author{
Cheng M. Moua* and Ray A. Dees ${ }^{\dagger}$ \\ NASA Dryden Flight Research Center, Edwards, California, 93523-0273
}

\begin{abstract}
Resurrecting the legacy Inner Loop Thrust Vectoring research flight controller to investigate the tail shock region brought unique challenges. This report documents these challenges and lessons learned from a stability and controls perspective. The flight test approach for flight envelope expansion and probing tests, as well as limited flight test results, are presented. Recent advances in sonic boom reduction technology have contributed to a resurgent interest in civilian supersonic cruise flight. These advances have focused only on fore body shaping, however, and little, if any, experimental flight data are available to develop and validate design tools for the tail shock region. In January of 2009, the NASA Dryden Flight Research Center completed research flights to investigate the tail shock region of a highly modified F-15 aircraft by probing the shock waves around it, using another F-15 aircraft. To adjust the lift distribution and plume shape, a decade-old research flight controller from the Inner Loop Thrust Vectoring project was required. To investigate the tail shock region, the lift distribution was changed by adjusting the canard position, and the plume shape was changed by adjusting the nozzle area and thrust vectoring.
\end{abstract}

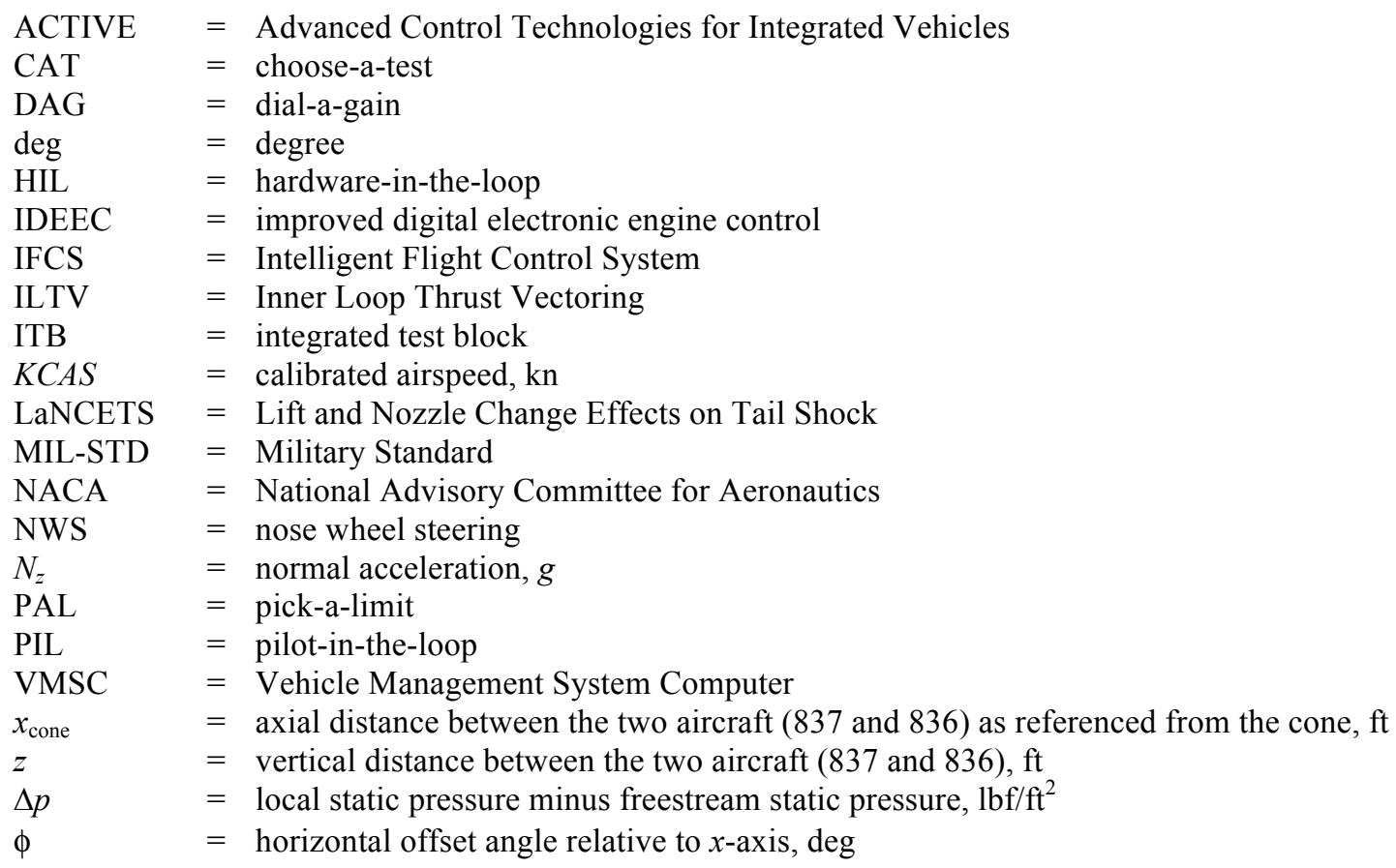

\footnotetext{
* Aerospace Engineer, Controls and Dynamics Branch, P.O. Box 273/MS 4840D Edwards, CA, AIAA Member.

$\dagger$ Aerospace Engineer, Simulation Engineering Branch, P.O. Box 273/MS 4840D Edwards, CA, Nonmember.
}

1 


\section{Introduction}

$\mathrm{R}$ cent advances, such as the successful demonstration of the propagation to the ground of a shaped sonic boom in the F-5 Shaped Sonic Boom Demonstrator (SSBD) project, ${ }^{1}$ and the successful demonstration of the Quiet Spike project, ${ }^{2-8}$ have contributed to a resurgent interest in civilian supersonic cruise flight. Sonic boom reduction technology, for example, may make overland civilian supersonic cruise a reality. Although the SSBD and Quiet Spike projects successfully validated design tools, it was focused on fore body shaping. Little, if any, experimental flight data are available to develop and validate design tools for the tail shock region, including shock-plume interactions. The Lift and Nozzle Change Effects on Tail Shock (LaNCETS) task was designed to investigate the tail shock region of an F-15 test aircraft (NASA NF-15B-837) by probing the shock waves around it, using another F-15 aircraft (NASA F-15B-836) (McDonnell Douglas Corporation, now the Boeing Company, St. Louis, Missouri). Figure 1 shows the two F-15 test aircraft. The approach for achieving the research objectives is to utilize the unique capabilities of the NASA NF-15B-837 aircraft to allow the adjustment of the nozzle area ratio, thrust vectoring, and/or canard positions. Changes to the nozzle area ratio and thrust vectoring affect plume shape, whereas canard positions affect the lift distribution over the aircraft.

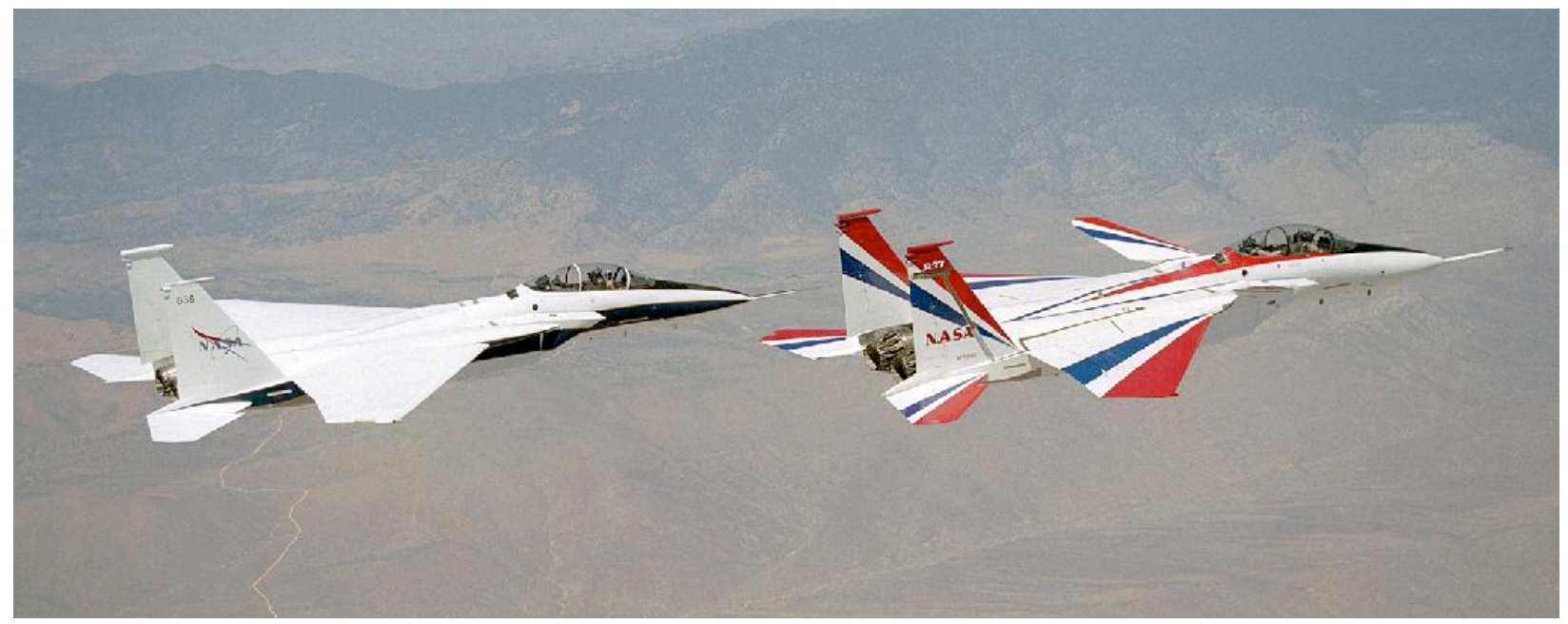

Figure 1. The NASA F-15B-836 and NF-15B-837 test aircraft.

The LaNCETS task falls under the Supersonic Project of the Aeronautics Research Mission Directorate Fundamental Aeronautics Program. The flight research from this task is required to satisfy a Congressional Milestone, FY08 Annual Performance Goal 8AT12, with the stated purpose to, "demonstrate a high-fidelity analysis technique for assessing the impact of nozzle plume effects on the off body flow field of a supersonic aircraft and validate predicted results within 5 percent of flight data."

This report discusses the challenges and lessons learned by resurrecting a decade-old research flight controller (F-15 ACTIVE ILTV) and expanding the flight envelope to support the LaNCETS task. This report focuses only on the stability and controls portion. Table 1 presents a summary of the challenges, problems, resolutions, and lessons learned on the LaNCETS project. 
Table 1. Summary of Lift and Nozzle Change Effects on Tail Shock (LaNCETS) challenges, resolutions, and lessons learned.

\begin{tabular}{|c|c|c|}
\hline Issues and Challenges & Mitigations/Resolutions & Lessons Learned \\
\hline $\begin{array}{l}\text { Lack of corporate knowledge on } \\
\text { ILTV research controller }\end{array}$ & $\begin{array}{l}\text { Gained familiarity with ILTV research } \\
\text { controller by finding and studying } \\
\text { preliminary design review (PDR) } \\
\text { slides, critical design review (CDR) } \\
\text { slides, technical brief slides, and flight } \\
\text { test reports }\end{array}$ & $\begin{array}{l}\text { Thoroughly document all pertinent } \\
\text { information and store it in an archival } \\
\text { system from which information can } \\
\text { be easily retrieved when needed }\end{array}$ \\
\hline Limited ILTV documentations & $\begin{array}{l}\text { Inquired about PDRs, CDRs, flight } \\
\text { test reports, and technical briefs to } \\
\text { management }\end{array}$ & $\begin{array}{l}\text { Document and archive all pertinent } \\
\text { information prior to close out of the } \\
\text { test program }\end{array}$ \\
\hline $\begin{array}{l}\text { Simulation development and } \\
\text { validation (check cases) }\end{array}$ & $\begin{array}{l}\text { Located hard-copy check case plots } \\
\text { from an ILTV research engineer for } \\
\text { simulation validation }\end{array}$ & $\begin{array}{l}\text { Formally document how the } \\
\text { simulation was validated and archive } \\
\text { all pertinent information, including } \\
\text { the check cases, for possible future } \\
\text { reference }\end{array}$ \\
\hline Stability margins (gain and phase) & $\begin{array}{l}\text { Performed stability margin analysis on } \\
\text { six-degree-of-freedom nonlinear } \\
\text { simulation using open loop transfer } \\
\text { function with frequency sweep }\end{array}$ & $\begin{array}{l}\text { When in doubt or if documentation is } \\
\text { lacking, perform stability margins } \\
\text { with LaNCETS configuration }\end{array}$ \\
\hline $\begin{array}{l}\text { Data sets verification and } \\
\text { validation }\end{array}$ & $\begin{array}{l}\text { Data sets were verified with the batch } \\
\text { simulation, piloted simulation, and } \\
\text { ground tests prior to flight. }\end{array}$ & $\mathrm{N} / \mathrm{A}$ \\
\hline HIL testing & $\begin{array}{l}\text { HIL test was attempted but after } 1 \\
\text { week of debugging and trouble } \\
\text { shooting the effort was abandoned; } \\
\text { instead, a thorough ground test was } \\
\text { used to meet the objectives of HIL } \\
\text { testing. }\end{array}$ & $\begin{array}{l}\text { It is extremely challenging and costly } \\
\text { to maintain a decade-old HIL } \\
\text { simulation in working condition; do } \\
\text { not rely on decade-old HIL } \\
\text { simulation for flight test risk } \\
\text { reduction }\end{array}$ \\
\hline $\begin{array}{l}\text { Unexpected thrust-vectoring } \\
\text { transient during simulation } \\
\text { disengagement }\end{array}$ & $\begin{array}{l}\text { Verified the occurrence of thrust } \\
\text { vectoring during disengagement in } \\
\text { ILTV flight; explained the anomaly }\end{array}$ & $\begin{array}{l}\text { Do not assume that if a problem was } \\
\text { not reported during a flight test } \\
\text { program that the problem does not } \\
\text { exist }\end{array}$ \\
\hline $\begin{array}{l}\text { LaNCETS flight envelope } \\
\text { clearance }\end{array}$ & $\begin{array}{l}\text { Buildup approach used for flight } \\
\text { envelope clearance progressing from } \\
\text { less risk to higher risk test points }\end{array}$ & N/A \\
\hline
\end{tabular}

\section{Aircraft Description}

The NASA NF-15B-837 shown in Fig. 1 is a highly modified preproduction F-15B airplane and is not representative of the production F-15 aircraft. Modifications to the vehicle include two canards mounted on the upper inlet area forward of the wing. The canards are modified F-18 horizontal tail surfaces, and their position in flight is scheduled as a function of angle of attack. An additional modification to the vehicle includes the incorporation of the F100-PW-229 Pratt \& Whitney (West Palm Beach, Florida) engines equipped with axisymmetric thrust-vectoring nozzles. The airplane is controlled by a quadruplex, digital fly-by-wire flight control system. All mechanical linkages between the control stick, rudder pedals, and control surfaces have been removed from the aircraft. ${ }^{9}$ The research vehicle has five different types of control surfaces: canards, ailerons, stabilators, rudders, and flaps. Each type has both a left and right surface. In addition to the control surfaces, thrust vectoring is also available.

The test aircraft, NASA NF-15B-837, was configured as it was during the Inner Loop Thrust Vectoring (ILTV) flight program. This configuration includes an additional research processor (the standard computing element 3 , 
SCE3) in each channel, the Vehicle Management System Computer (VMSC), and the ability to add trim command biases to canard positions, nozzle area ratios, and thrust vectoring through the use of data sets. Figure 2 shows a block diagram of the ILTV avionics system. Data sets consist of programmed test inputs (PTIs) that define "trims" to change the nozzle area ratio and/or canard positions. The trims are applied as increments to the normally commanded positions.

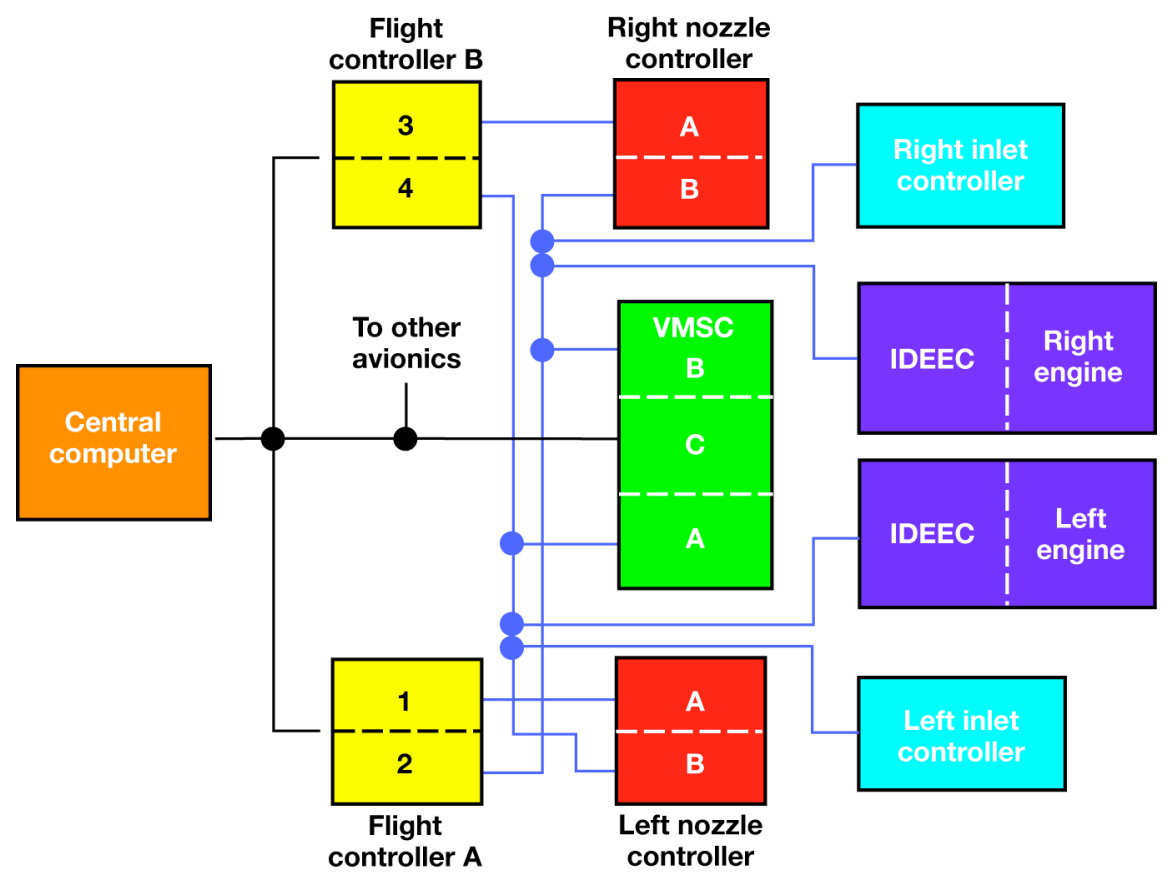

Figure 2. Inner Loop Thrust Vectoring (ILTV) avionics system.

In the reversionary ILTV configuration, envelope limits for the control laws are set using the pick-a-limit (PAL) feature; the control laws are specified using dial-a-gain (DAG) options; and test input data sets are picked using the choose-a-test (CAT) functionality. Data sets are loaded into the VMSC as a group and as many as fifteen inputs can be included in a group. The LaNCETS test inputs were performed using DAG 28, which locks out the use of feedback thrust vectoring, and PAL 8. This PAL-DAG combination was flown at Mach 1.2 and an altitude of $30,000 \mathrm{ft}$ during the ILTV program and was used as part of the envelope expansion for LaNCETS.

Research control software is loaded into the SCE3 for use during flight tests. The aircraft performs normal operations (takeoff, landing, and so forth) using the conventional mode control laws. The pilot engages the research control law by depressing the nose wheel steering (NWS) button when the appropriate PAL, DAG, and CAT are set at the desired flight condition. For safety reasons, extra attention and consideration were given with multiple options to automatically or manually disengage from the research flight control. The system automatically reverts back to the conventional mode when predefined envelope limits are exceeded (such as altitude, airspeed, accelerations, and so forth), as defined by the PAL. Manual disengagements are commanded by pilot depression of the NWS switch, paddle switch, trigger switch, or enhanced switch. When the NWS switch is depressed, the data set (CAT) becomes inactive while the research controller is still active. The NWS switch disengagement allows for effective testing of the CATs without resetting the PAL and DAG. Pilot depression of the paddle, trigger, or enhanced switch disengages from the research flight control. The difference between the paddle, trigger, and enhanced switch disengagements is the 1-s fader transition to the conventional controller with the trigger switch. The paddle switch and enhanced switch revert back to the conventional controller without a fader.

The probing aircraft, NASA F-15B-836, has a special, sonic boom-measuring nose boom installed. The special nose boom has been used previously on projects such as the SSBD. ${ }^{1}$ It is a modified NACA-style nose boom and has additional static pressure ports where the angle-of-attack and sideslip vanes normally would be. 


\section{Inner Loop Thrust Vectoring (ILTV) Flight Controller}

The ILTV research flight controller was extensively flight tested in $1998 .{ }^{10}$ The ILTV research flight controller was selected to support the LaNCETS task for its capability to add canard trim biases, nozzle area ratio biases, and thrust-vectoring biases. Although no modifications were made to the ILTV flight controller, bringing back a decadeold flight controller for flight-testing is not without its challenges and obstacles. The LaNCETS flight test points were not flown during the ILTV program. Furthermore, the required LaNCETS probing flight conditions are outside the previously cleared ILTV flight envelope. Therefore, additional aeroservoelasticity, structural, and stability and controls analyses were required to demonstrate flight safety before the actual flight envelope expansion.

The ILTV longitudinal mixer provides four modes of control blending between the aerodynamic and thrustvectoring commands. In the nominal mode is a 50-50 control blending. Another similar mode has 75 percent thrustvectoring control and 25 percent aerodynamic surface control. The last two modes have thrust-vectoring control only or aerodynamic surface control only. Although the no-thrust-vectoring mode is the least interesting mode from a controls research perspective, this mode is the most suitable to support the LaNCETS task and is the only mode discussed in this report. Note that when the no-thrust-vectoring mode is used, thrust-vectoring biases may still be commanded with the preprogrammed data sets.

\section{Simulation Development, Validation, and Verification}

Simulation was an integral part of the LaNCETS project. Considerable effort was made to develop, verify, and validate the LaNCETS simulation. This section discusses the challenges, problems, and lessons learned during the simulation effort.

\section{A. Simulation Description}

The NASA Dryden Flight Research Center (Edwards, California) simulation facility includes a dedicated fixedbase real-time pilot-in-the-loop (PIL) F-15B simulator with standard stick and rudder pedal inceptors for pilot control. Also included are head-up display, cockpit pilot flight instruments, and external real-time visual imagery. Oblate earth nonlinear six-degree-of-freedom equations of motion are used. The simulation may be operated in a real-time piloted mode or in a remote batch mode as an engineering analysis tool. Batch simulation runs can also be scripted to facilitate automated analysis. ${ }^{11}$

\section{B. Simulation Development and Verification}

The utilization of the ILTV controller for the LaNCETS task created some unusual challenges for the simulation group at NASA Dryden. In addition to the requirement for a PIL real-time simulation, both hardware-in-the-loop (HIL) and non-real-time batch simulations were required. The non-real-time simulation was primarily needed to perform data set checkout and loads analyses.

In the roughly 10 years since the ILTV project concluded flight-testing, many changes have been made to the Dryden simulation hardware and software. From a hardware standpoint, the original ILTV simulation computer hardware (Silicon Graphics, Inc., now Silicon Graphics International, SGI, Fremont, California) was no longer available, because the SGI systems had been phased out and replaced by Sun Microsystems, Inc. (Santa Clara, California), equipment. Furthermore, the software interfaces (primarily MIL-STD-1553) had been customized for the SGI environment, which meant that the 1553 software would need to be extensively modified to conform to the Sun environment. Another aspect considered was that the Dryden simulation infrastructure (referred to now as the "core" simulation) had undergone significant enhancements beginning in late 2004 and continuing to the present day. ${ }^{12}$ Corporate knowledge about the older Dryden simulation infrastructure and usage had waned over time as the simulation engineers and research engineers began using the newer simulations.

The inability to utilize the ILTV simulation without extensive updates was unfortunate for two reasons. First, a significant programming effort was necessary to port the real-time simulation to the Sun environment. Second, an extensive validation effort would have to be performed for this newly developed simulation, which was no small task.

At the outset of the real-time simulation development effort, the F-15 Intelligent Flight Control System (IFCS) flight test project was underway, using the same test aircraft (NASA NF-15B-837) as that used in the LaNCETS project. A version of the F-15 837 simulation already had been updated to support the IFCS project and included most of the standard features of a modern Dryden core simulation. For support reasons it was decided to retain the capability to support both projects (IFCS and LaNCETS) in the same simulation. Thus the LaNCETS modifications were made to the IFCS simulation. 
As the conversion effort proceeded, it became clear that if the data set validation, engagement-disengagement transient analysis, and loads analysis were not performed, the schedule would be negatively impacted. The LaNCETS (F-15-837) simulation would be capable of supporting not only the real-time requirements (PIL and HIL) but also the non-real-time needs. The LaNCETS (F-15-837) simulation was not yet operational, however, so a rush effort was undertaken to port the original ILTV non-real-time (F-15 ACTIVE v39) simulation to the Sun environment. This software port did not require hardware specific modifications and was relatively straightforward. In addition, there was no attempt to incorporate any of the newer core simulation infrastructure enhancements. This updated non-real-time simulation (F-15 ACTIVE v39) was made available to the research engineers in time to complete the required analyses before the flight readiness review (FRR). The FRR is a committee made up of nonproject engineers to assess the overall safety and readiness of the project for flight.

The LaNCETS simulation was separated from the IFCS simulation to simplify the task and speed up the development. This decision led to the timely completion of the LaNCETS simulation for support of PIL and HIL real-time studies and non-real-time analysis.

\section{Simulation Validation}

Validation of the LaNCETS simulations (F-15 ACTIVE v39 and F-15-837) presented some unusual challenges and difficulties for the simulation group. When a new simulation is validated, typically two or three possible approaches are used. One approach is to validate the new simulation against an existing validated simulation. Although the ILTV simulation had been validated in 1998, it was no longer possible to run that simulation, so this option was ruled out. Another approach is to compare the new simulation results against existing flight data. This approach uses pilot inputs from the recorded flight data to drive the simulation. By recording the simulation data, one can compare them against the flight data results. Typically, this approach requires significant effort and is limited by the available flight data results. The third approach (the one eventually used) is to validate the new simulation by comparing the LaNCETS simulation results with the results from the original check case supplied by the contractor.

A major difficulty faced in completing these validations was the scarcity of check case results (the truth model results). The original ILTV simulation validation was accomplished by comparing simulation results with data from 61 check cases provided by the contractor. It was discovered that the data provided by the contractor and the ILTV simulation results had not been formally archived. An extensive search, however, resulted in hard-copy printouts of the check case comparisons from 1998 that were retained by one of the research engineers. These comparisons consisted of side-by-side plots of data supplied by the contractor and the ILTV simulation results performed in 1998.

Because the LaNCETS task requires only one configuration setting (PAL 8, DAG 28), the validation could be limited to that setting. Of the original 61 ILTV check cases, only 3 were found to meet this setting and also contained the hard-copy printouts. The validation consisted of these 3 check cases. Some validations were performed by visually comparing the plotted data, side by side. For the 3 check cases with digital data, the validation was done by overplotting the ILTV results against the new simulation results. A more thorough validation involving many more check cases would have been preferred. Only straight and level flight was required for LaNCETS, however, so the FRR decided that these comparisons were sufficient for validation. The passage of time had made the LaNCETS simulation validation difficult, compounded by the failure to properly archive the original comparison data. Fortunately, the two new simulations were not entirely new but were essentially conversions of a previously validated simulation. An entirely new simulation would, of course, require a more extensive validation.

A valuable lesson learned is the importance of formally documenting how the simulation was validated and archiving all pertinent information, including the check cases, for future reference. Although hard-copy printouts of check cases were eventually located for the LaNCETS project, critical data may be unobtainable for comparison and therefore cannot be relied upon.

\section{Hardware-in-the-Loop and Ground Tests}

In addition to software simulation validation and verification at NASA Dryden, an HIL test at the Boeing Company's simulator (St. Louis, Missouri) was attempted to verify and validate newly developed data sets, quantify worst-case effects of failure modes, and verify pilot-vehicle interface. The HIL test was much more difficult than expected. The outmoded hardware and software required extensive tweaking and debugging for the simulation to work properly. Additionally, corporate knowledge to properly set up and run the HIL simulator with the ILTV configuration was lacking. The HIL simulator was debugged for 1 week, but the ILTV configuration still would not run. As such, HIL testing was abandoned. In lieu of the HIL test, extensive ground tests of the ILTV configuration 
were performed. All data sets planned for flight were verified to add the appropriate biases as programmed. Pilotvehicle interface functionality of the ILTV research flight controller worked as expected.

\section{Stability and Controls Simulation Analysis}

Although the ILTV test team showed adequate stability margins for the flight project in 1998, little detail was documented or readily available in the no-thrust-vectoring configuration (PAL 8, DAG 28) for support of the LaNCETS task. Adjusting the canard trim biases, nozzle area ratios, and thrust vectoring further added uncertainty in stability, aeroservoelasticity, and structural integrity of the aircraft and required simulation analysis for preparation of the flight test. To show adequate stability margins and handling qualities, stability and controls analyses were performed using the six-degree-of-freedom nonlinear simulation. Time history aircraft responses to pitch, roll, and yaw doublets were well damped for various canard trim biases $\left(0^{\circ}, \pm 3.3^{\circ}, \pm 5.4^{\circ}\right)$, nozzle area ratios, and thrust vectoring. Figure 3 shows a sample time history aircraft response to a pitch doublet with various canard position trim biases.

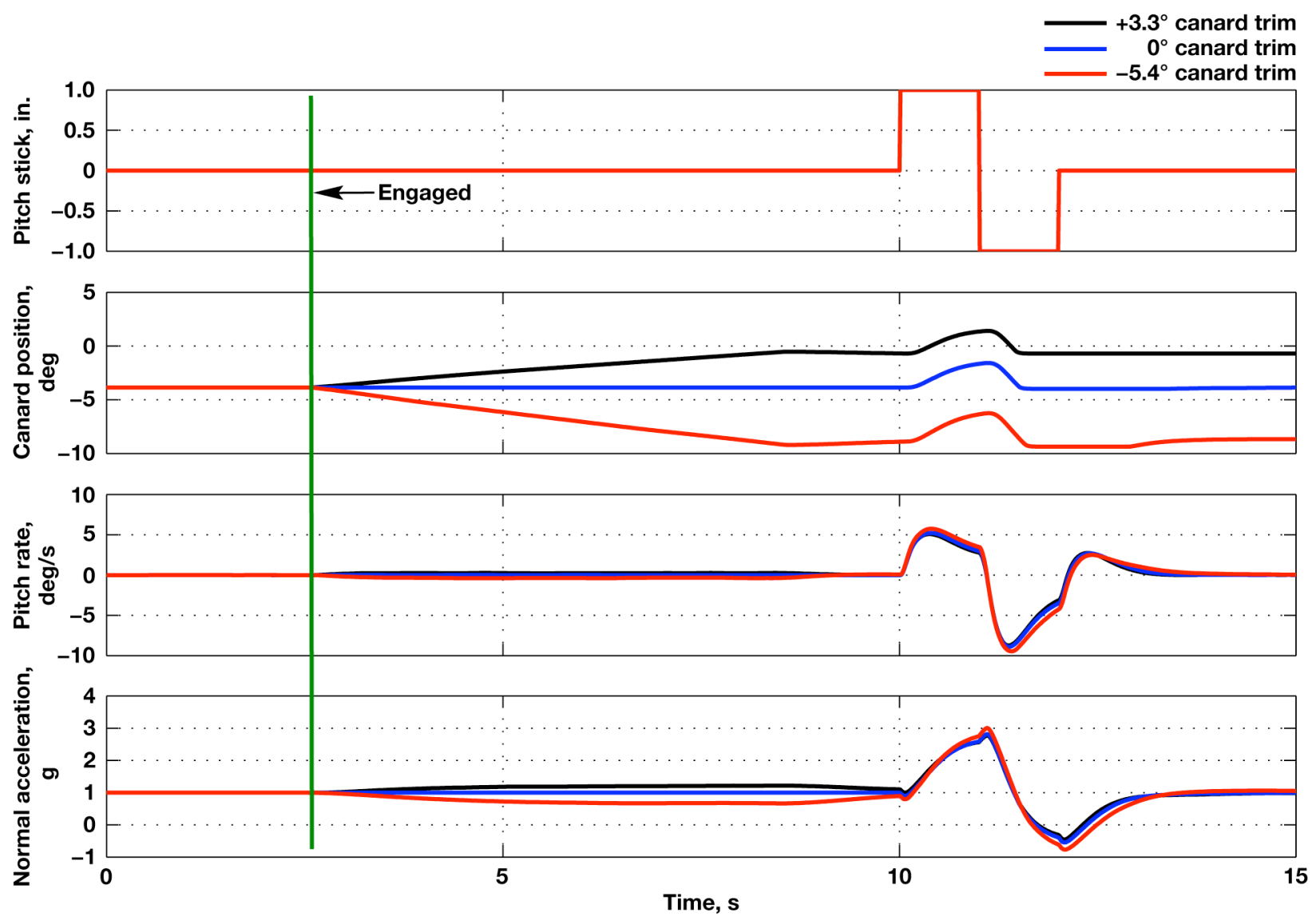

Figure 3. Simulated aircraft dynamic response to pitch doublets with canard position trim biases; Mach 1.4, $40,000 \mathrm{ft}$.

A nonlinear frequency response analysis was performed with the current Dryden ILTV simulation for all eight flight conditions, three canard position trim biases $\left(0^{\circ},+3.3^{\circ},-5.4^{\circ}\right)$, and five surface loops (collective stabilators, differential ailerons, collective canards, collective rudders, and differential stabilators). The analysis confirmed adequate stability margins for the flight conditions and configurations that were planned for the flight test. The lowest gain margin and phase margin were $8.8 \mathrm{~dB}$ and $61.4^{\circ}$, respectively. Figure 4 shows a sample Bode plot of the symmetric stabilator loop at Mach 0.9 and an altitude of 20,000 ft. In addition to stability and controls analyses, engagement and disengagement transients between the baseline conventional controller and the ILTV research 
controller were performed with the canard trim biases, nozzle area ratios, and thrust-vectoring angles at the flight conditions planned for the flight test.
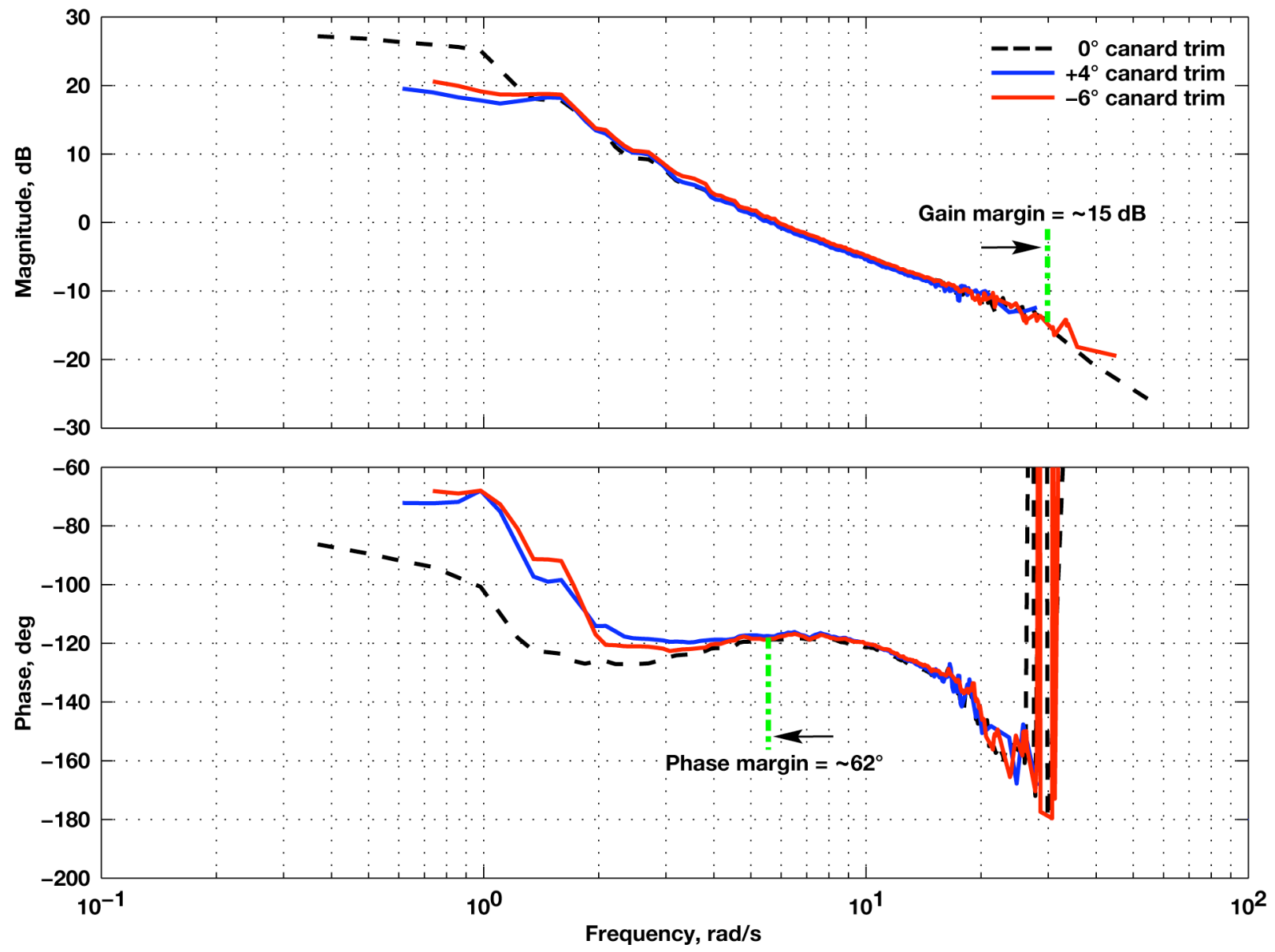

Figure 4. Frequency sweep symmetric stabilator loop Bode plot; Mach 0.9, 20,000 ft.

\section{A. Engagement Transient Analysis}

There were no engagement transients (conventional mode to enhanced mode) in the subsonic flight regime. In the supersonic flight regime (Mach numbers greater than 1.2), transients as high as $+1 g$ were observed in the batch simulation. This problem was known and reported during ILTV HIL testing and was observed during ILTV simulation check cases. Although engagement transients were observed with the simulations, they did not appear during the ILTV flights. On the three ILTV flights with PAL 8 DAG 28 engagements, no transients were observed. On flight 123 at Mach 1.2 and an altitude of 30,000 ft, engagements with PAL 8 DAG 28 did not produce any transients as noted and observed from the simulation. Therefore, the project concluded that engagement transients are artifacts of the simulation only. No work was performed to match the simulation to the flight, because the simulation was considered conservative and the results were acceptable.

\section{B. Disengagement Transient Analysis}

A disengagement transient analysis was performed with the batch simulation for all flight conditions intended for the flight tests. Three canard trim biases $\left(0^{\circ},+3.3^{\circ},-5.4^{\circ}\right)$ and four disengagements methods (NWS switch, paddle switch, trigger switch, and enhanced switch) were used in the analysis. The worst-case normal acceleration, $N_{z}$, transient of $1.85 \mathrm{~g}$ was observed while the NWS switch was used at Mach 0.9 and an altitude of 20,000 ft, with a canard position trim bias of $-5.4^{\circ}$. Although the $N_{z}$ transient of $1.85 \mathrm{~g}$ seems large, it took $0.85 \mathrm{~s}$ to reach the peak, without any pilot interaction. Figure 5 shows the worst-case $N_{z}$ transients. When the worst-case transient test point 
was evaluated in the piloted simulation with the pilot reacting to the $g$-onset, minimal transient was observed. These nonpiloted disengagement transients were deemed acceptable.

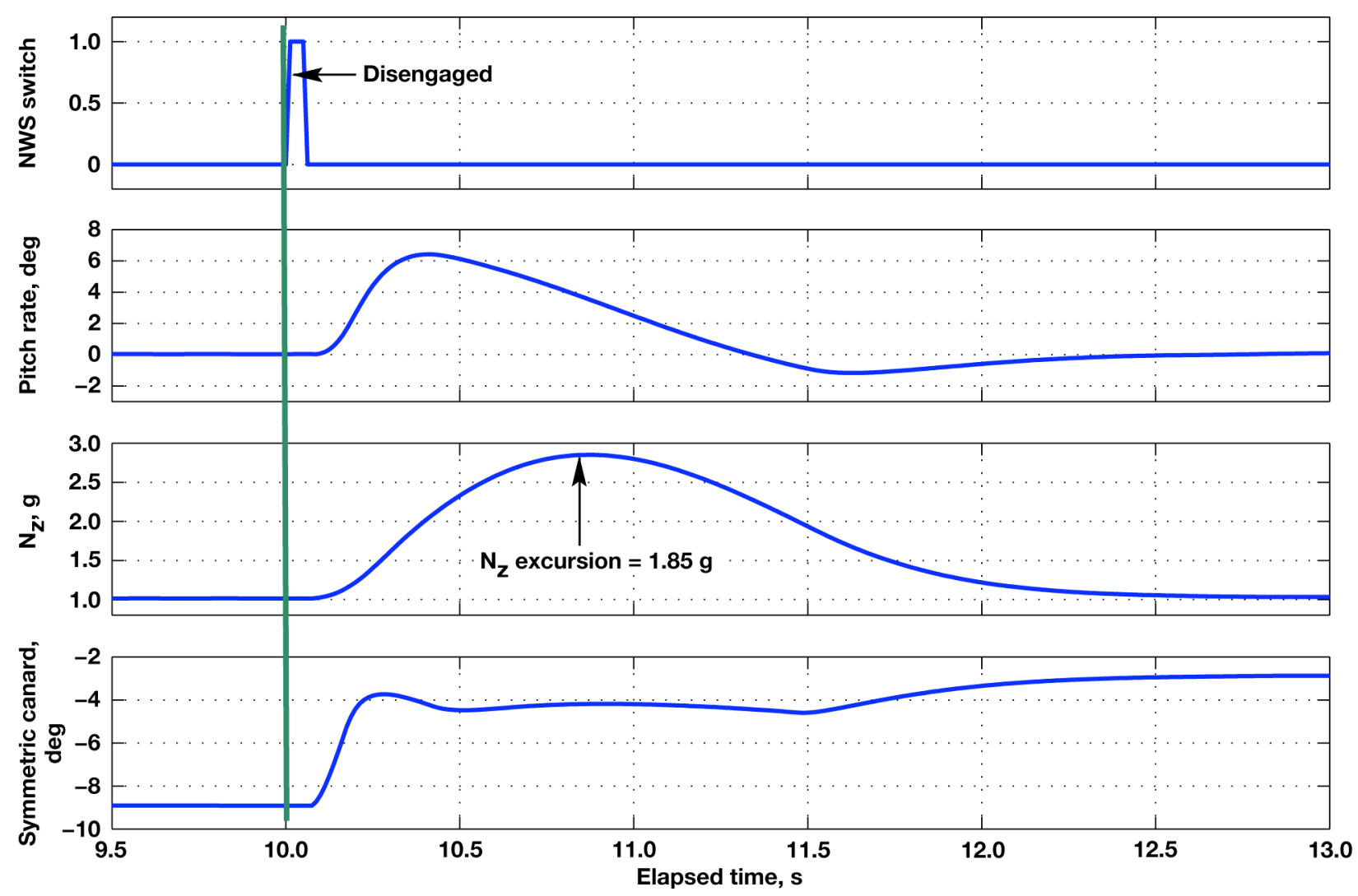

Figure 5. Worst-case simulated disengagement transient; canard trim bias of $-5.4^{\circ}$, Mach $0.9,20,000 \mathrm{ft}$.

Although pitch nozzle transients were not observed nor documented during the ILTV program, they were observed during the LaNCETS simulation disengagement evaluation with the trigger switch. Figure 6 shows the simulation disengagement thrust-vectoring transient. The validity of the LaNCETS simulation that was heavily relied upon to enable flight-testing was in question because of this transient anomaly. The LaNCETS project was unsure whether this anomaly was an artifact of the simulation or a real transient of the ILTV flight controller. To further compound the problem, most of the ILTV flight test members are no longer available for consultation, and the few who are still available have no recollection of this anomaly. This small yet unexpected transient anomaly created a delay in the LaNCETS task. Many hours of searching, reviewing, and analyzing decade-old ILTV flight data confirmed that the pitch nozzle transient observed in the LaNCETS simulation was real. The pitch nozzle anomaly was probably not identified, documented, or reported during the ILTV program because the no-thrustvectoring DAG was not the focus. As a result, the occasional blip during disengagement from DAG 28 was not noticed. A valuable lesson learned from this anomaly is the importance of thoroughly documenting flight reports and archiving flight data for future use. Although the ILTV flight reports help resolve and clarify the thrustvectoring transient anomaly on the LaNCETS project, searching for the flight reports took considerable effort. The flight reports were not properly archived for easy retrieval. Another lesson learned is not to assume that if a problem was not reported during a flight test program, then the problem does not exist. 


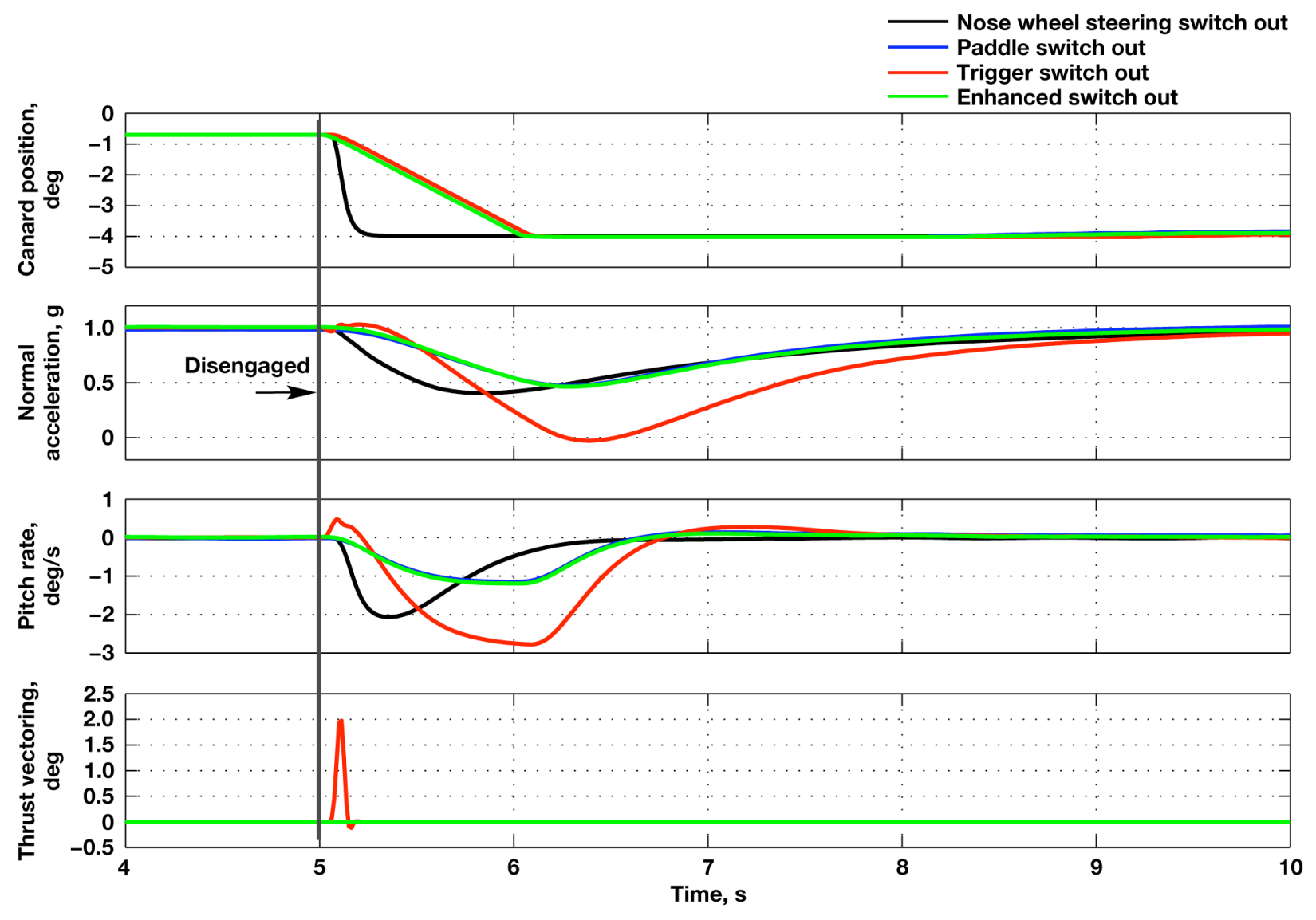

Figure 6. Simulated disengagement thrust-vectoring transient; canard trim bias of $+3.3^{\circ}$, Mach $1.4,40,000 \mathrm{ft}$.

Once the pitch nozzle transient was determined to be real, the focus shifted to better understand the trigger switch disengagement sequence. Simulation results revealed an approximate 0.05 -s window in which the ILTV controller transitions from a no-thrust-vectoring to a thrust-vectoring mode (DAG 28 to DAG 20) before the aircraft down modes to the conventional mode. The thrust-vectoring transient is observed during this 0.05 -s window, as shown in Fig. 7. Thrust-vectoring transients would not have occurred if the transition from DAG 28 to DAG 20 had been synchronized up with the transition from the enhanced mode to the conventional mode. 


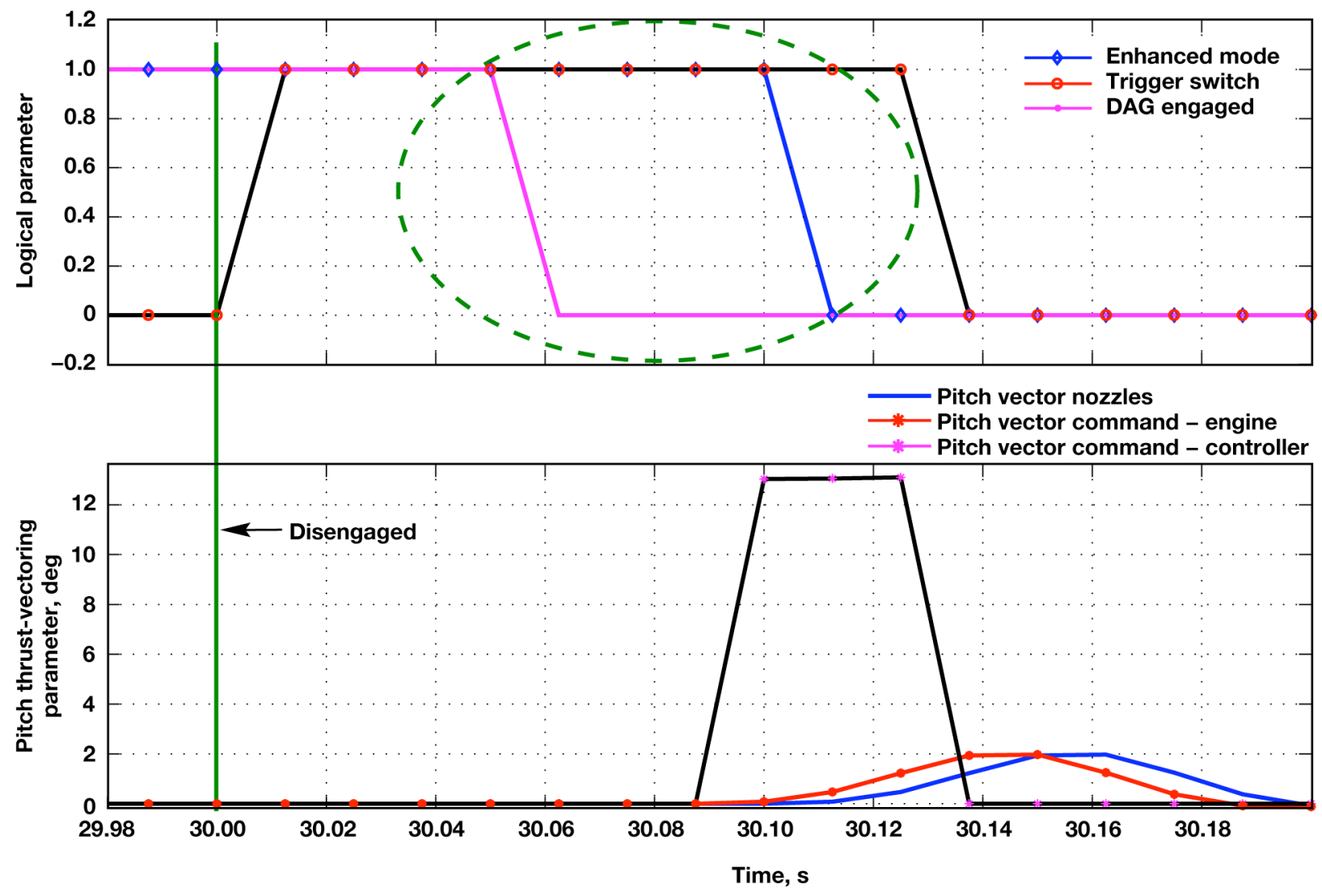

Figure 7. Trigger switch disengagement sequence; Mach 1.4, 40,000 ft., dial-a-gain (DAG) 28.

In addition to the batch simulation analysis, piloted simulation evaluation was performed for aircraft dynamic responses and engagement-disengagement transients. All simulated flight conditions at worst-case canard trim biases, nozzle area ratios, and thrust vectoring were performed. Aircraft dynamic responses and engagementdisengagement transients were manageable with the pilot counteracting the transients.

\section{Flight Test}

A total of 13 flights were conducted to support the LaNCETS project for the flight conditions shown in Fig. 8. A buildup approach was used to ensure flight safety. Flight envelope clearance and data set checkout were performed in the subsonic flight regime before proceeding to the supersonic flight regime. Flight envelope clearance was tailored from the ILTV flight program, which consisted of raps and doublet maneuvers. These maneuvers were considered sufficient to reveal any aeroservoelasticity, stability, or structure loads with the ILTV research flight controller, because probing was mainly conducted at level flight. During supersonic flight envelope clearance, it was discovered that the engine controller prohibits changes to the nozzle area ratio for safety reasons. Therefore, shock wave probings were performed with canard position trim biases and thrust-vectoring biases but not with nozzle area ratios. 


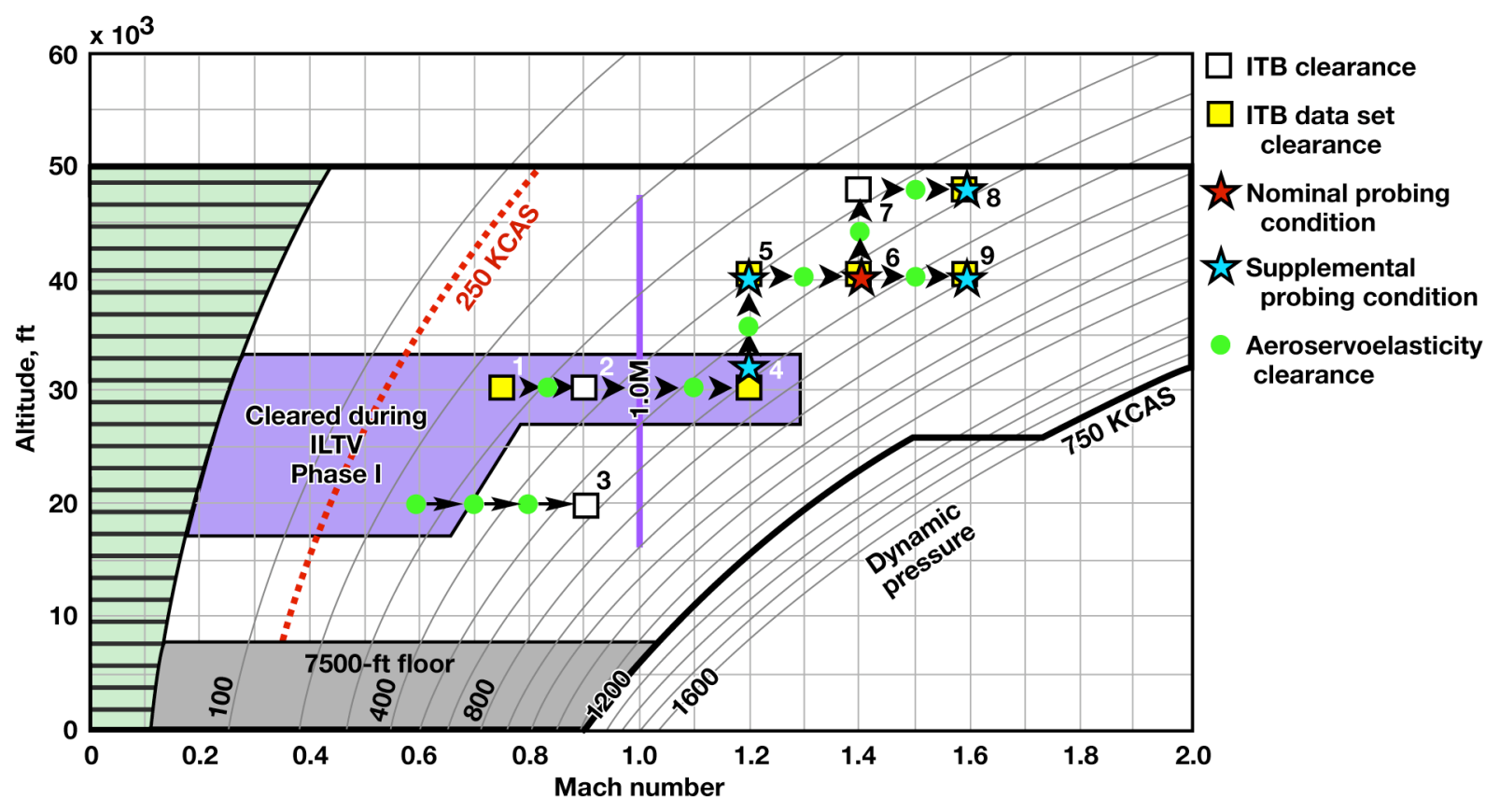

Figure 8. Lift and Nozzle Change Effects on Tail Shock (LaNCETS) flight conditions.

To validate the analysis tools, flight data were compared with simulation data for the flight envelope clearance maneuvers after each flight. The same piloted stick inputs and initial flight conditions from the flight data were used to drive the simulation for comparisons. As shown in Fig. 9, excellent matches were observed for the flight envelope clearance doublets maneuvers. Aircraft dynamic responses were well damped for the flight conditions flown. Disengagement transient comparisons between the flight and simulation were adequate. Although the simulation consistently overpredicted the normal load factor by as much as $0.7 \mathrm{~g}$ during disengagements of the research flight controller with piloted inputs, these matches were better than the matches without the piloted stick inputs. Figure 10 shows a sample plot of the disengagement from the research flight controller with a canard position bias of $+3.3^{\circ}$. A normal loading $\left(N_{z}\right)$ mismatch of approximately $0.25 \mathrm{~g}$ was observed during the disengagement at Mach 1.4 and an altitude of $40,000 \mathrm{ft}$. 

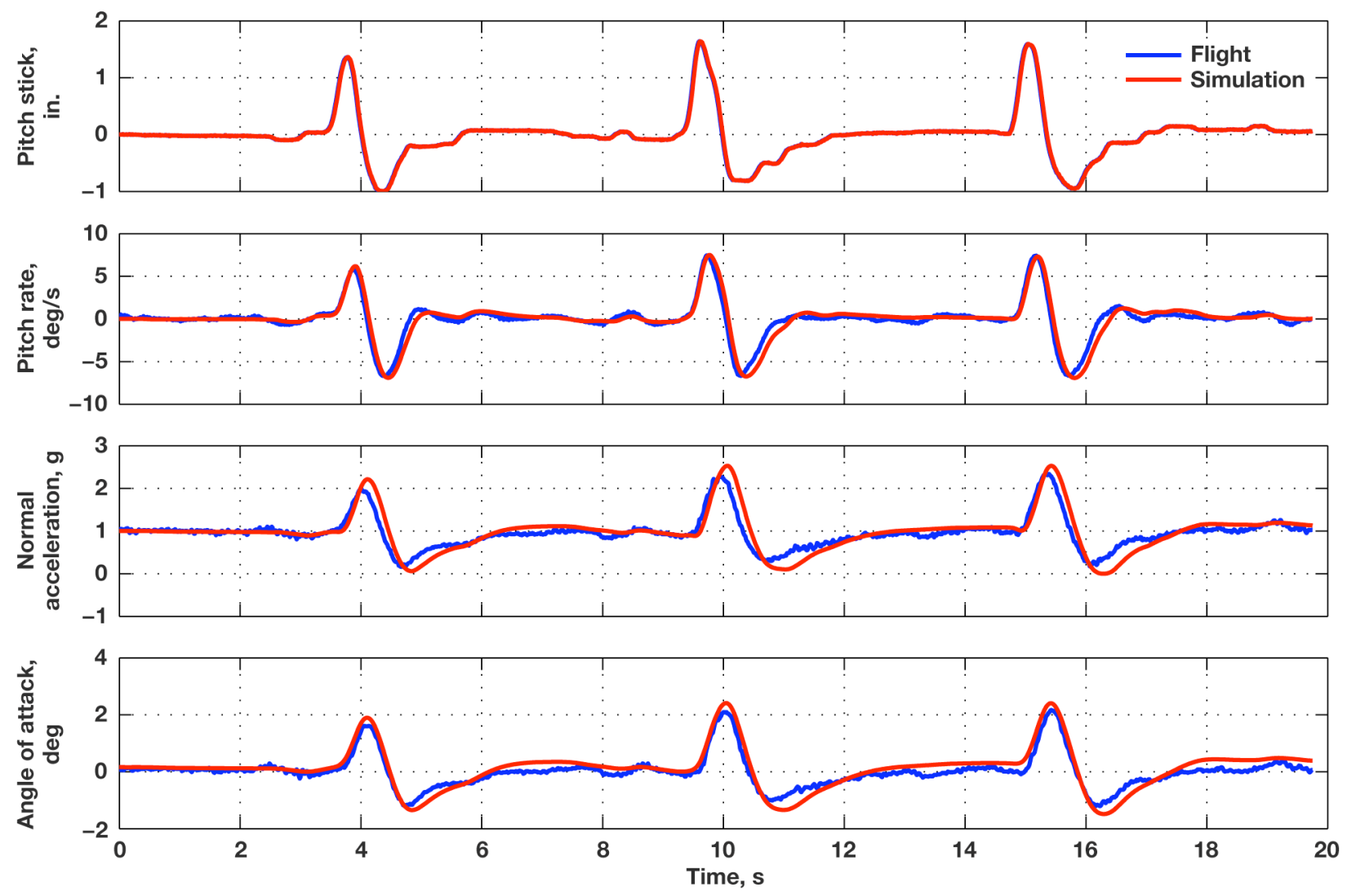

Figure 9. Comparison of flight with simulation, flight envelope expansion doublets; canard trim bias of $+3.3^{\circ}$, flight 0245, Mach 1.6, 40,000 ft. 


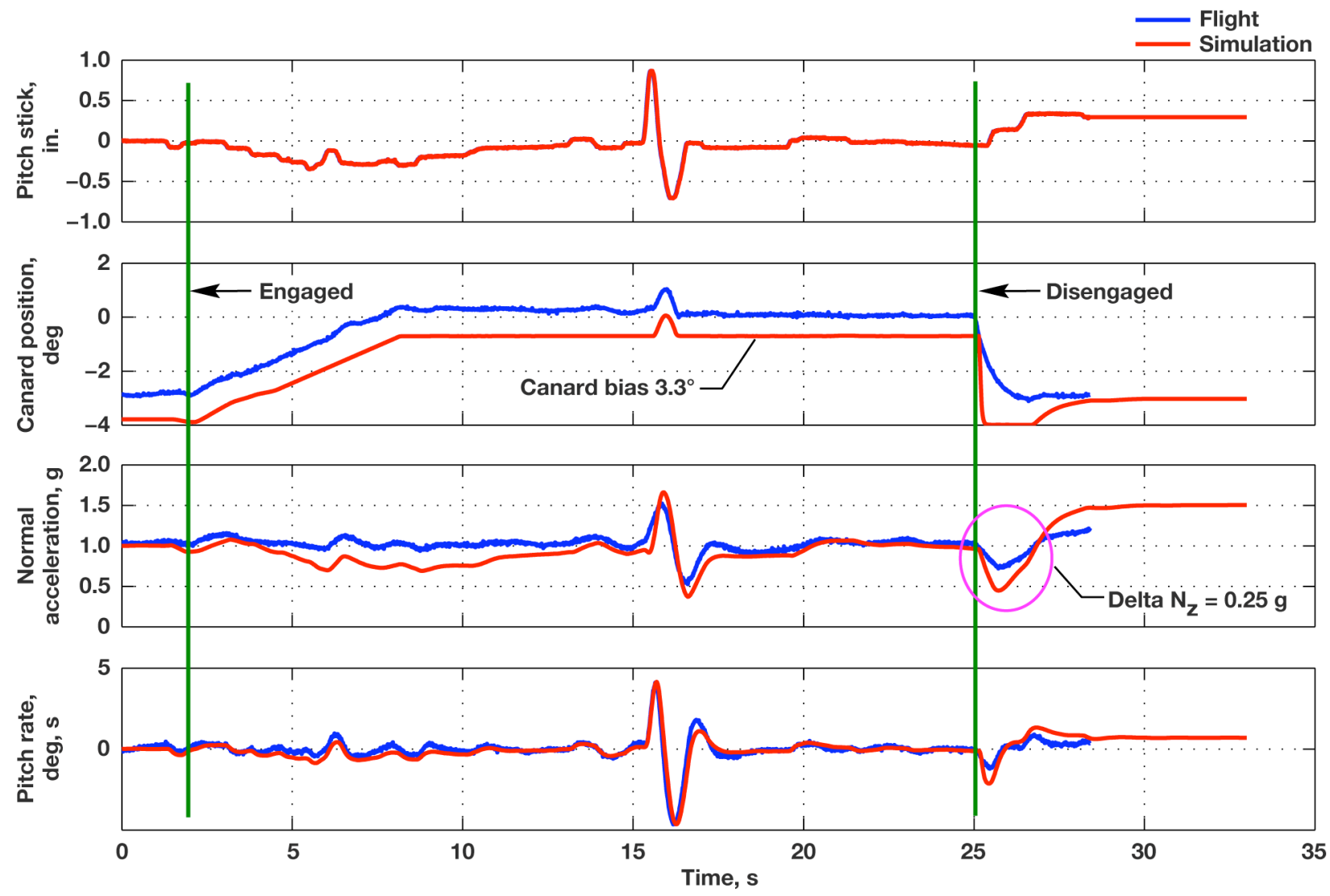

Figure 10. Comparison of flight with simulation, disengagement transient; canard trim bias of $+3.3^{\circ}, \mathrm{Mach}$ $1.4,40,000 \mathrm{ft}$.

Shock wave probings of canard trim biases and non-feedback thrust-vectoring biases were successfully completed in the LaNCETS project. Non-feedback thrust-vectoring biases of $+6^{\circ},-6^{\circ}$ pitch angles and $\pm 3^{\circ}$, $\pm 6^{\circ}$ yaw angles at Mach 1.2 and 40,000 ft, and $+8^{\circ},-8^{\circ}$ pitch angles at Mach 1.4 and 40,000 ft were flown for shock wave probing. Canard trim biases were completed at flight conditions of Mach 1.2 and 40,000 ft, Mach 1.4 and $40,000 \mathrm{ft}$, Mach 1.6 and 40,000 ft, and Mach 1.4 and 48,000 ft. A sample probing plot of the F-15 aircraft is shown in Fig. 11, which shows a very detailed pressure signature superimposed over a picture of the F-15 aircraft, scaled such that the bow and recompression shocks line up with the nose and tail. The other shocks in the aft region are labeled, with significant shocks occurring in the exhaust plume region. These trailing shocks were one of the primary focuses of LaNCETS and have proven the most difficult to model. ${ }^{13}$ 


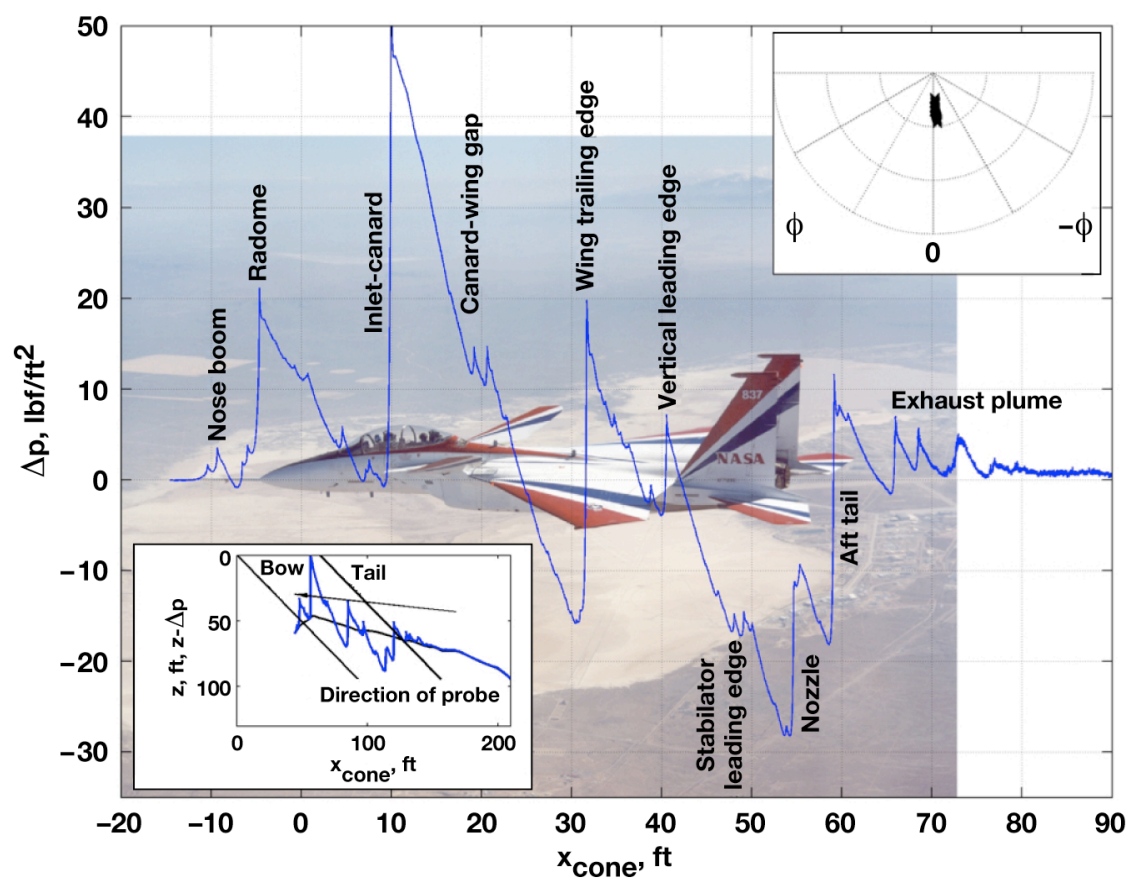

Figure 11. Sample probing result.

\section{Conclusion and Lessons Learned}

Challenges were encountered and many lessons were learned from resurrecting the legacy Inner Loop Thrust Vectoring (ILTV) research flight controller to investigate the tail shock region of an F-15 aircraft by adjusting the lift distribution and plume shape. Corporate knowledge of legacy systems is difficult to retain when personnel changes over time in an organization. One way to not lose the corporate knowledge is to thoroughly document all pertinent information and store it in an archival system for easy retrieval of information when needed. A recommendation for any flight test program is to document and archive all pertinent information before closeout of the test program. Even the simple tasks of adjusting canard surface positions and nozzle area ratios using data sets required extensive research by the new team members.

New advances in software and hardware require continual upgrades of the simulation environment. Migrating a legacy simulation to the current simulation environment requires proper documentation of the interfaces, validation check cases with simulation scripts, and configuration control of software versions. Lack of archived ILTV simulation data made a straightforward validation task more difficult than it had to be.

With the limited ILTV simulation documents, the Lift and Nozzle Change Effects on Tail Shock (LaNCETS) simulation was completed and validated for stability and controls analyses that showed adequate margins. Additionally, an engagement-disengagement transient analysis was also performed and showed manageable transients. An unexpected small pitch nozzle transient during one of the disengagements questioned the validity of the newly modified simulation. A thorough review of ILTV flight data confirmed the small pitch nozzle and validated the newly modified simulation. A buildup approach was used for the flight tests starting at subsonic test conditions before proceeding to supersonic test conditions. Flight envelope clearance and data set verifications were performed before the probing test conditions. Shock wave probing of canard trim biases and thrust-vectoring biases were successfully completed in the LaNCETS project.

\section{References}

${ }^{1}$ Haering, E.A., Jr., Murray, J.E., Purifoy, D.D., Graham, D.H., Meredith, K.B., Ashburn, C.E., and Stucky, M., Lt. Col., "Airborne Shaped Sonic Boom Demonstration Pressure Measurements with Computational Fluid Dynamics Comparisons," AIAA-2005-0009, Jan. 2005.

${ }^{2}$ Wolz, R., “A Summary of Recent Supersonic Vehicle Studies at Gulfstream Aerospace,” AIAA-2003-0558, Jan. 2003.

15

American Institute of Aeronautics and Astronautics 
${ }^{3}$ Henne, P.A., "Case for Small Supersonic Civil Aircraft," AIAA Journal of Aircraft, Vol. 42, No. 3, May-June 2005, pp. $765-774$.

${ }^{4}$ Henne, P.A., Howe, D.C., Wolz, R.R., and Hancock, J.L., Jr., Supersonic Aircraft with Spike for Controlling and Reducing Sonic Boom, U.S. Patent No. 6,698,684 B1, issued March 2, 2004.

${ }^{5}$ Howe, D.C., "Sonic Boom Reduction Through The Use of Non-Axisymmetric Configuration Shaping," AIAA-2003-0929, Jan. 2003.

${ }^{6}$ Howe, D.C., "Improved Sonic Boom Minimization with Extendable Nose Spike,” AIAA-2005-1014, Jan. 2005.

${ }^{7}$ Cowart, R., and Grindle, T., "An Overview of the Gulfstream/NASA Quiet Spike ${ }^{\mathrm{TM}}$ Flight Test Program," AIAA-2008-0123, Jan. 2008.

${ }^{8}$ Smolka, J.W., Cowart, R.A., Molzahn, L.M., et al., "Flight Testing of the Gulfstream Quiet Spike ${ }^{\mathrm{TM}}$ on a NASA F-15B," Society of Experimental Test Pilots 51st Symposium and Banquet, SETP, Anaheim, California, Sept. 26-29, 2007.

${ }^{9}$ Richwine, D.M., "F-15B/Flight Test Fixture II: A Test Bed for Flight Research,” NASA TM 4782, 1996.

${ }^{10}$ Brown, A., “ACTIVE wraps up Inner Loop Thrust Vectoring phase I tests," The Dryden X-Press, Vol. 40, Issue 24, Dryden Flight Research Center, Edwards, California, Dec. 30, 1998.

${ }^{11}$ Norlin, K.A., "Flight Simulation Software at NASA Dryden Flight Research Center," NASA TM-104315, 1995.

${ }^{12}$ Curlett, B.P., "A Software Framework for Aircraft Simulation,” NASA/TM-2008-214639, 2008.

${ }^{13}$ Bui, T.T., "CFD Analysis of Nozzle Jet Plume Effects on Sonic Boom Signature," AIAA-2009-1054, Jan. 2009. 
Challenges and Lessons Learned From Resurrecting a Legacy Research Flight Controller

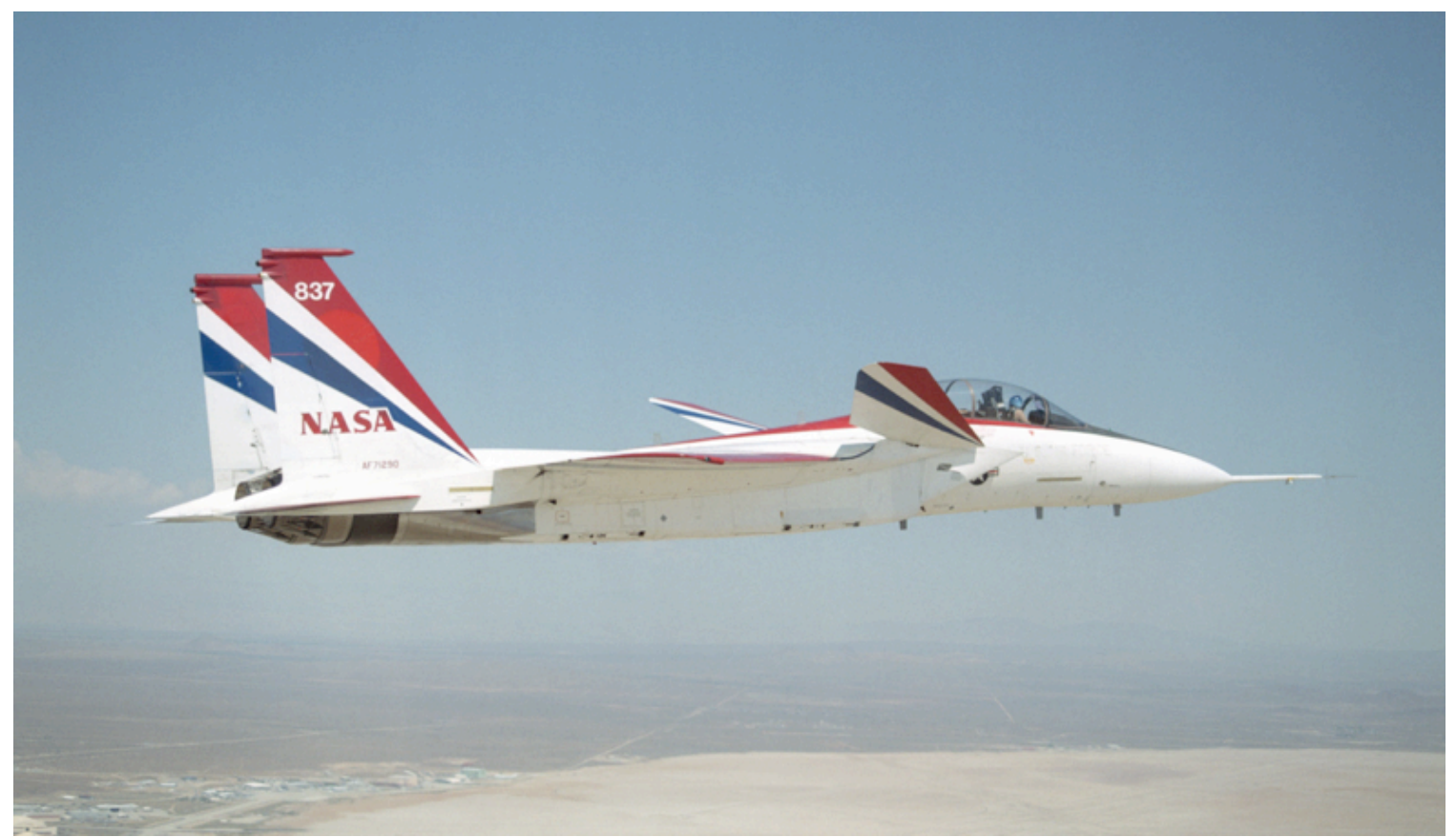

Cheng Moua

NASA Dryden Flight Research Center

X X Iyden Flight Research Cenfer 


\section{Outline}

- Introduction

- Aircraft Description

- ILTV Flight Controller

- Simulation Development and V\&V

- HIL and Ground Test

- Stability and Controls Simulation Analysis

- Flight Test

- Conclusion and Lessons Learned 


\section{Introduction}

- Recent advances in sonic boom reduction technology led to a resurgent interest in civilian supersonic cruise flight

- F-5 SSBD

- F15 Quiet Spike

- Fore body shaping only

- LaNCETS objective:

- Investigate the tail shock region of an F-15 test aircraft by changing the lift distribution and plume shape for design tool validation

- ARMD FAP Supersonic project funding

- Congressional Milestone, FY08 Annual Performance Goal

- "demonstrate a high-fidelity analysis technique for assessing the impact of nozzle plume effects on the off body flow field of a supersonic aircraft and validate predicted results within 5 percent of flight data."

- This report discusses challenges and lessons learned by resurrecting a decade-old research flight controller to support LaNCETS objective

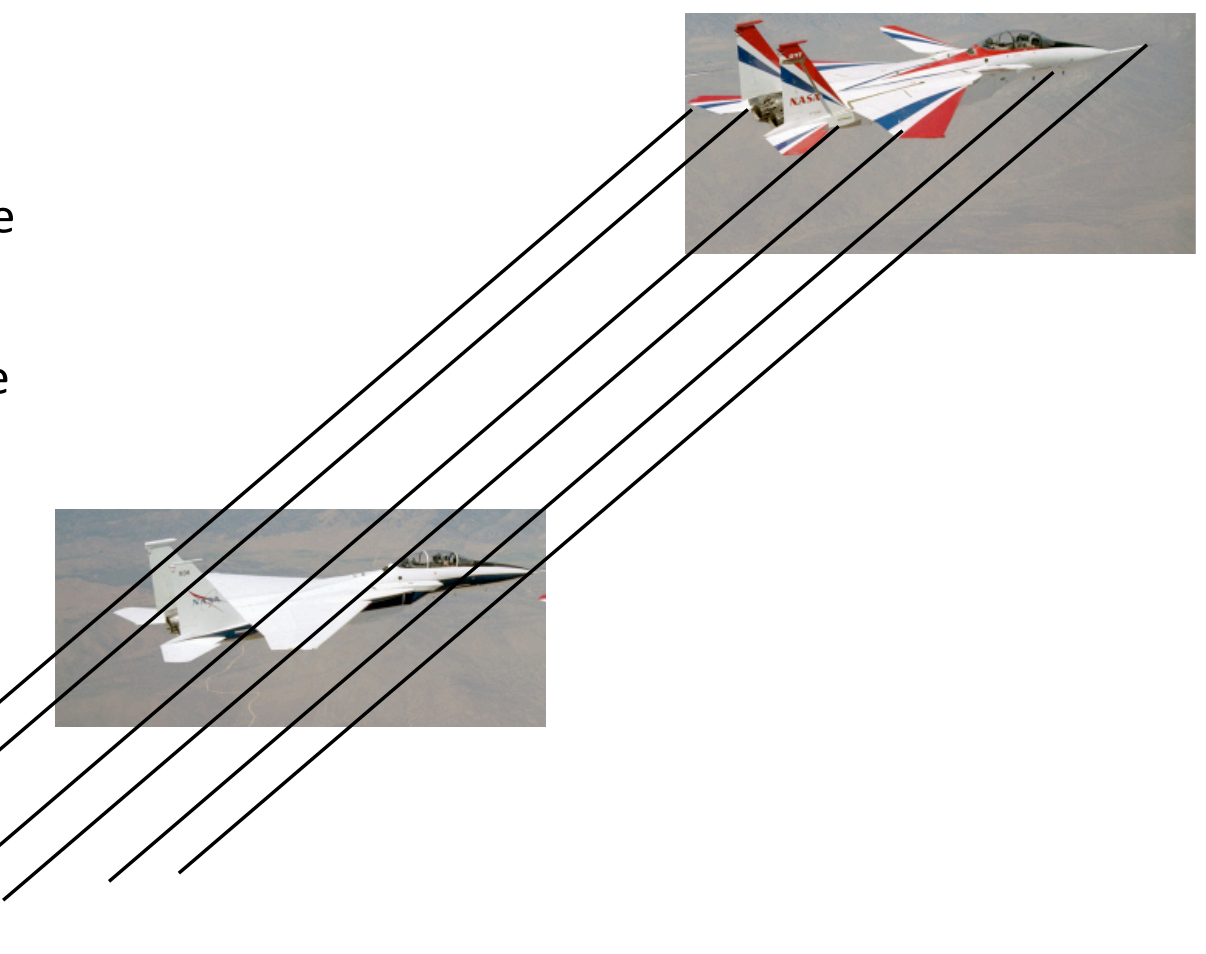




\section{Aircraft Description}

- NF-15-837

- Highly modified preproduction F15-B

- Canards addition

- Removal of mechanical control linkages

- Research Controller Engage/ Disengage

- PAL/DAG/CAT

- NWS, Paddle, Trigger, Enhanced Switches

- Datasets

- Add trim biases

- Symmetric canards

- Non-feedback thrust vectoring

- Nozzle area ratio

- F-15B-836

- Special sonic boom measuring nose boom

- Used in NASA SSBD and Quiet Spike projects 


\section{PAL/DAG/CAT}

- PAL: Pick A Limit

- Allows for a selection of a limited envelope

- 16 PAL sets numbered 0-15

- PAL 8: (Minimum Yaw Vectoring $2^{\circ}$ )

$-\mathrm{Nz}+6 /-1 \mathrm{~g}, \mathrm{Ny}+/-2 \mathrm{~g}, \mathrm{P}+/-300^{\circ} / \mathrm{sec}, \mathrm{Q}+/-60^{\circ} / \mathrm{sec}, \mathrm{R}+/-60^{\circ} / \mathrm{sec}$

- DAG: Dial A Gain

- Allows selection of predefined set of system gains

- 16 DAG sets numbered 0, 21-35

- DAG 28: No vectoring

- CAT: Choose A Test (AKA Dataset)

- Allows for canned inputs to surfaces 


\section{PAL}

Pick - A - Limit (PAL) Operation

Select PAL Set from Menu CONV Mode Must Be Engaged Box Indicates Selection

Number Appears in 'Ready' Position
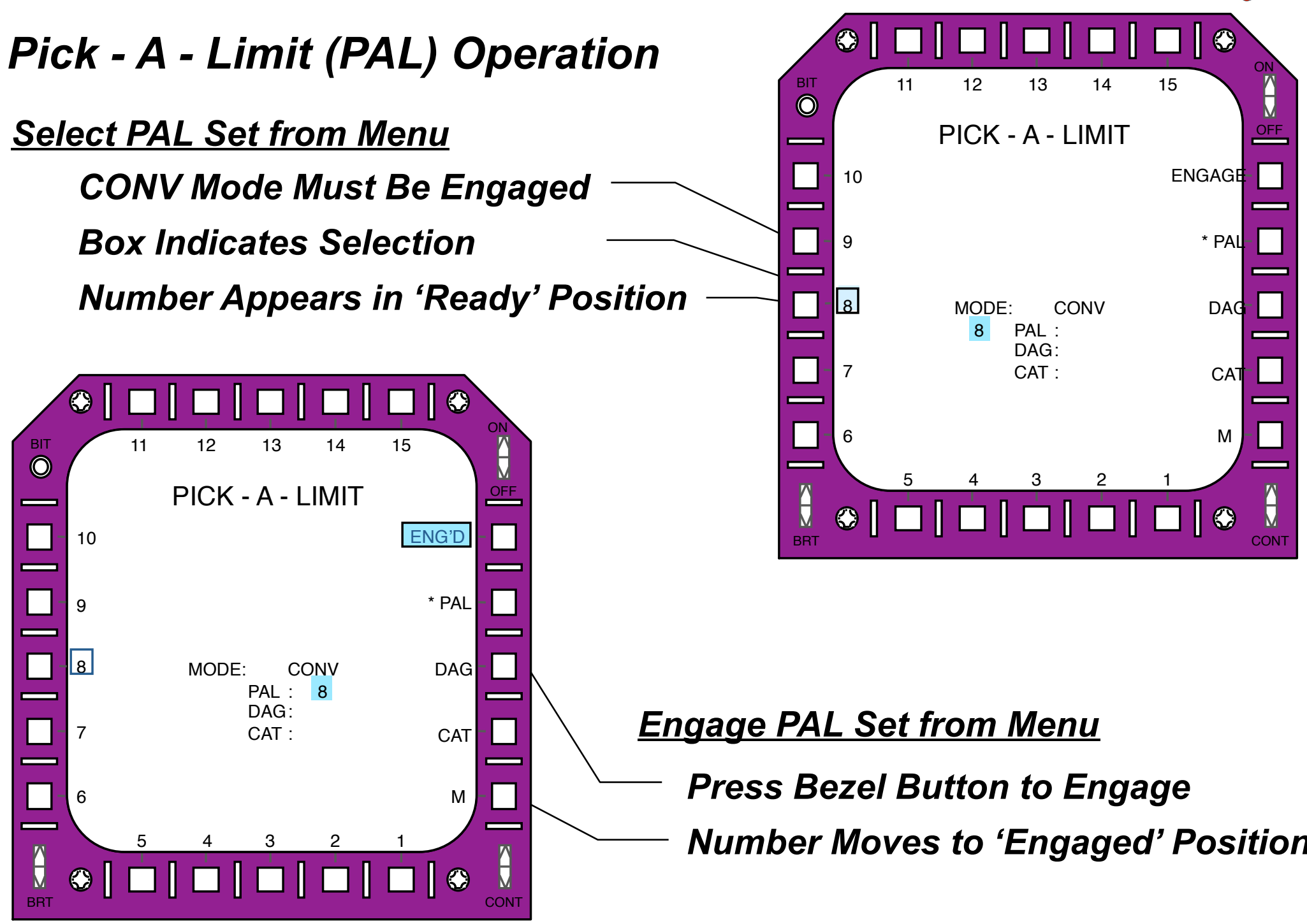

Engage PAL Set from Menu

Press Bezel Button to Engage Number Moves to 'Engaged' Position 
Dial - A - Gain (DAG) Operation

Select DAG Set from Menu CONV Mode Must Be Engaged Box Indicates Selection Number Appears in 'Ready' Position
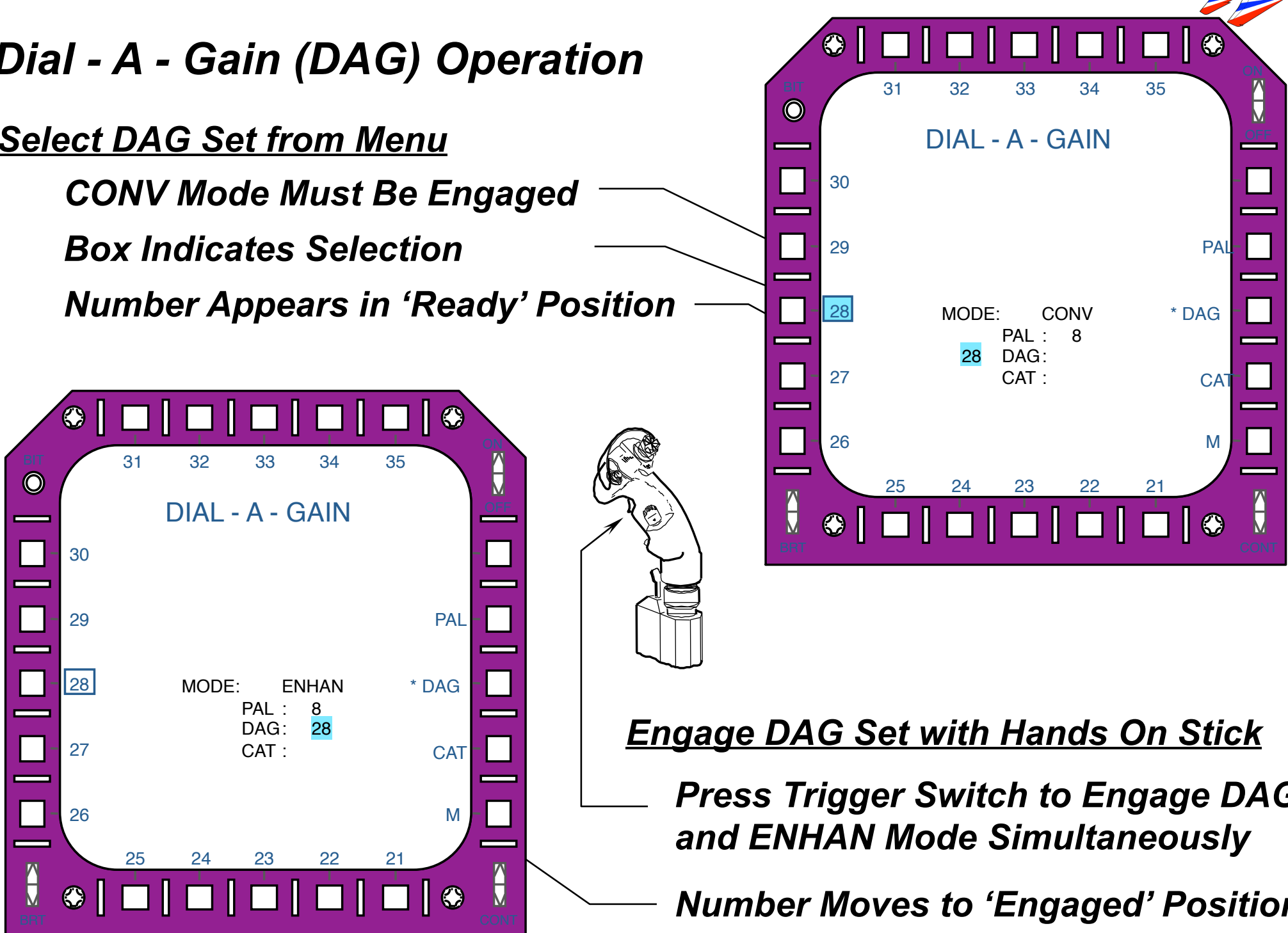

Engage DAG Set with Hands On Stick Press Trigger Switch to Engage DAG and ENHAN Mode Simultaneously Number Moves to 'Engaged' Position 


\section{CAT/Dataset}

Choose - A - Test (CAT)

- Adds Outer Loop 'Trim' Signals to Control Effector Commands

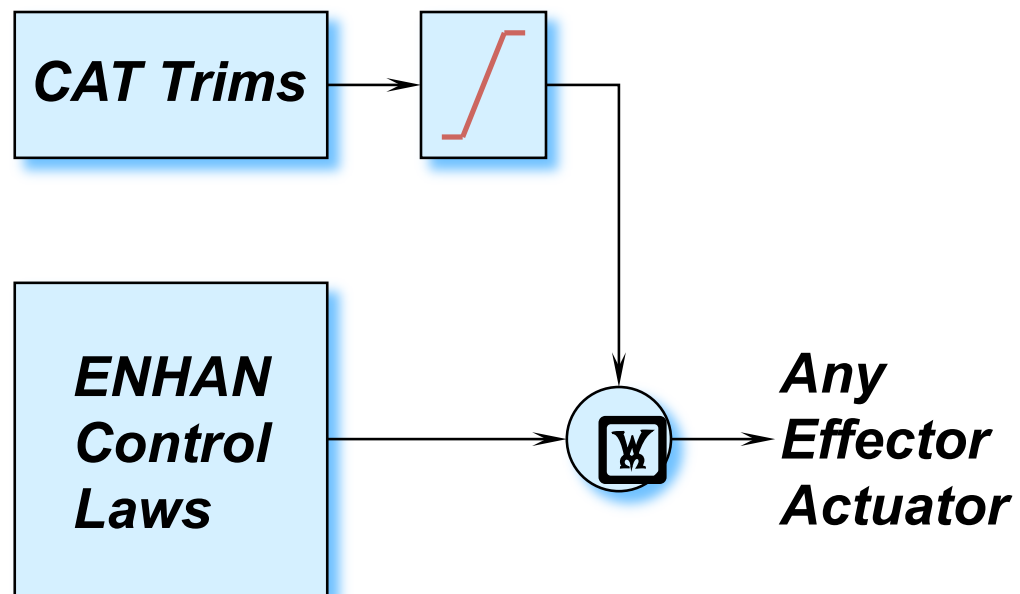

- Programmable Signal Characteristics

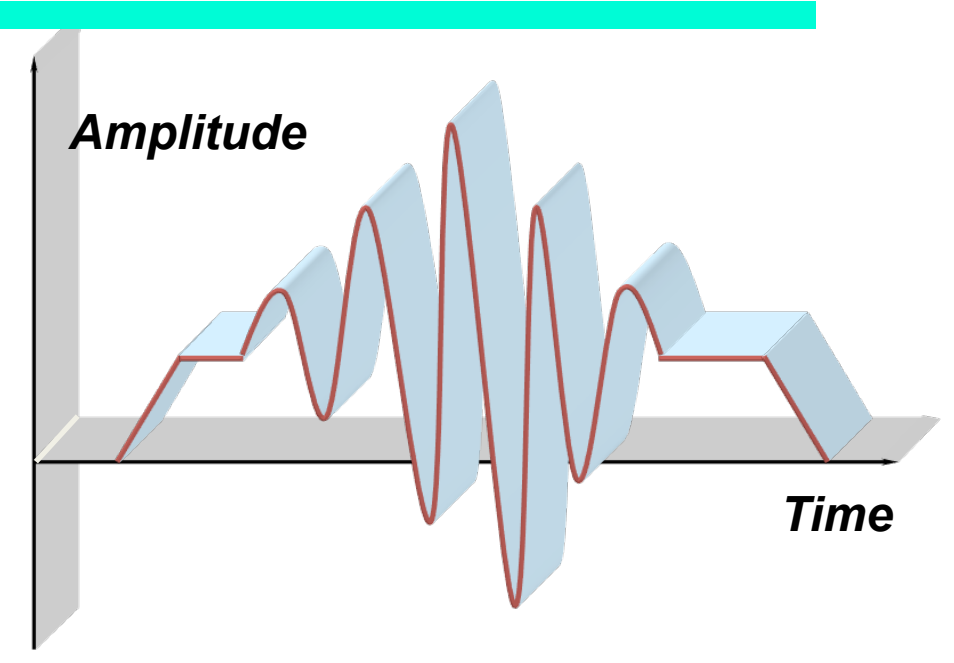

- Trim Signals Composed from Piecewise Linear Shaping Functions to both Canard and Nozzle Area Ratio 


\section{ILTV Controller}

- ILTV Controller

- Legacy research flight controller flown in the late 1990s

- Capable to add biases: canard trim, nozzle area ratio, and thrust vectoring

- Longitudinal mixer modes:

- Control blending 50\%-50\% aerodynamic \& thrust vectoring

- Control blending $25 \%-75 \%$ aerodynamic \& thrust vectoring

- $100 \%$ thrust vectoring control

- $100 \%$ aerodynamic control (DAG 28)

- Challenges

- Simulation Development and VnV

- Dataset Verification

- LaNCETS probing flight conditions are outside previously cleared ILTV flight envelope

- ASE, SnC simulation analyses required for flight safety

- Flight envelope expansion 


\section{Simulation Development}

- NASA Dryden F-15B simulator

- Fixed based real time PIL

- Oblate earth nonlinear 6dof

- Simulation Challenges

- Changes to Dryden simulation since ILTV project

- Hardware

- Migration from Silicon Graphics International to Sun Microsystems

- ILTV software interface (MIL-STD 1553) customized to SGI

- Extensive modification required to conform to Sun environment

» Significant programming effort to port real time sim to the Sun environment

» Extensive validation for newly developed sim

- Dryden simulation infrastructure enhancements (Core Sim)

- Loss of corporate knowledge of the older Dryden simulation infrastructure and usage

- Multiple simulation releases required

- Early dataset validation, load analysis, and engage/disengage transient analysis for FRR

- Port original ILTV non-real time (F-15 ACTIVE v39) sim to Sun environment

- No hardware specific modification

- No Core Sim infrastructure enhancements

- Relatively straight forward task 


\section{Simulation Development \& VnV}

- Simulation Development

- Decision made to develop one simulation to support two concurrent projects

- IFCS and LaNCETS use same NF15-837 platform

- IFCS sim already in Core Sim infrastructure

- Initially LaNCETS modifications were made to IFCS sim

- More difficult than originally thought

- Separation from IFCS sim simplify the task and speed up the develop

- Necessary for timely completion of LaNCETS sim

- Simulation VnV

- Simulation Validation Challenges

- Failure to properly archive the original comparison data

- Extensive search resulted in hard-copy printouts of check case comparisons from 1998

- Scarcity of check case

- 3 out of 61 original check cases were in LaNCETS configuration setting (PAL 8, DAG 28)

- Lessons Learned

- Formally document how the simulation was validated

- Archive all pertinent information, including check cases for future reference 


\section{HIL and Ground Test}

- HIL test at Boeing St Louis attempted but eventually abandoned

- Decade old hardware and software required extensive tweaking and debugging for the sim to work properly

- Corporate knowledge to properly setup and run the HIL simulation with ILTV configuration is lacking

- Extensive ground tests of ILTV configuration performed in lieu of HIL test

- Datasets were verified

- PVI functionality verified

- Engagement/Disengagement transients verified 


\section{Stability and Controls Simulation Analysis}

- ILTV stability margin analysis lacking in the no-thrustvectoring configuration (PAL 8, DAG 28)

- Adjusting canard trim biases, nozzle area ratios, and thrust vectoring biases add uncertainties in stability, ASE, and structural integrity

- Stability and Controls analysis performed in 6dof nonlinear simulation

- Doublets (pitch, roll, yaw axes)

- 8 flight conditions

- Canard trim biases (0 $[\mathrm{W}$,

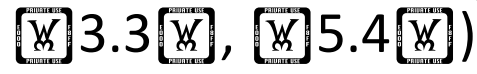

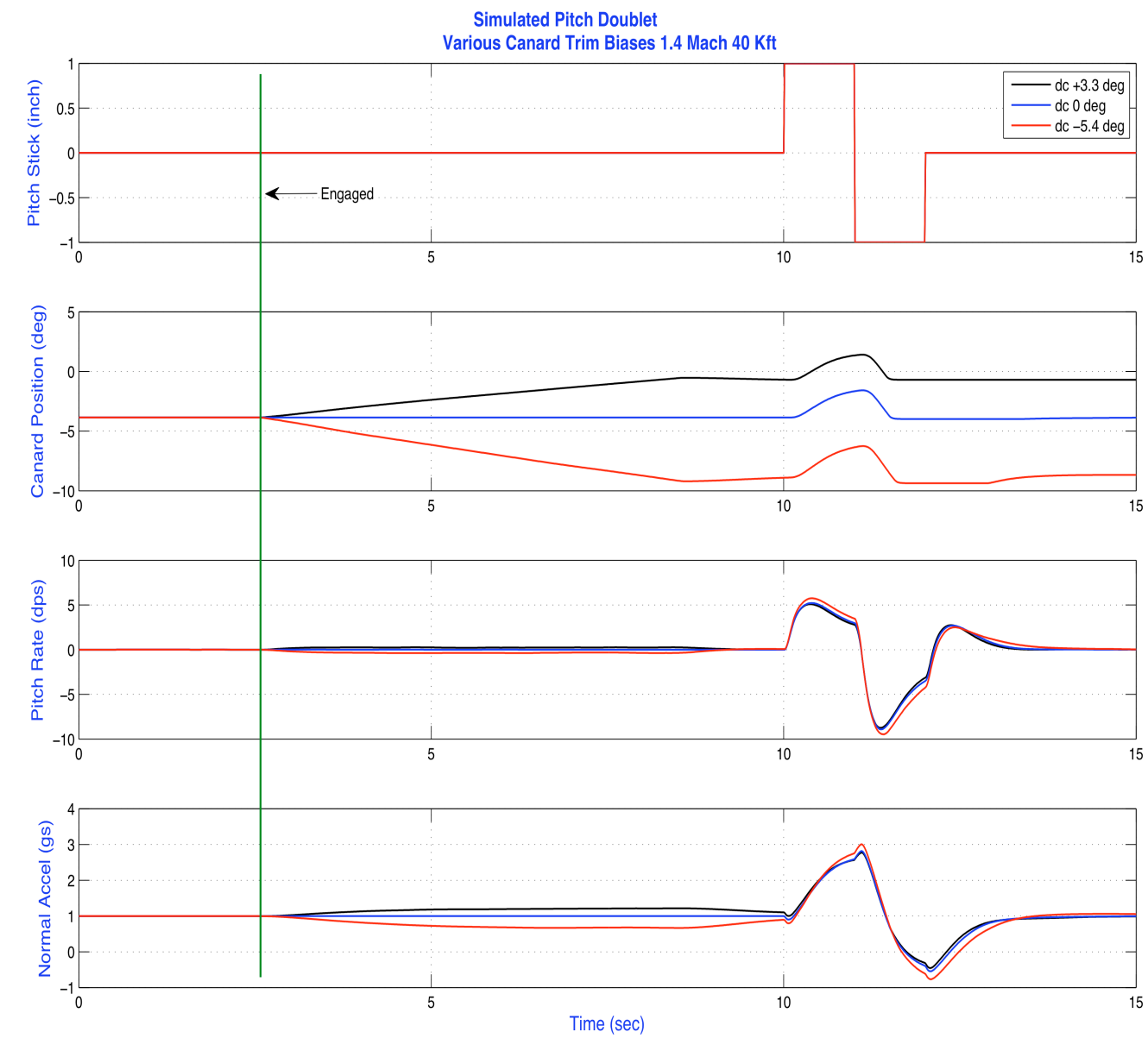

- Nozzle area ratios

- Thrust vectoring biases 


\section{Stability and Controls Simulation Analysis}

- Non-linear frequency response analysis

- 8 flight conditions

- Canard trim biases (0ㅇ, +3.3 으, -5.4 ㅇ)

- 5 surface loops

- Collective stabilators

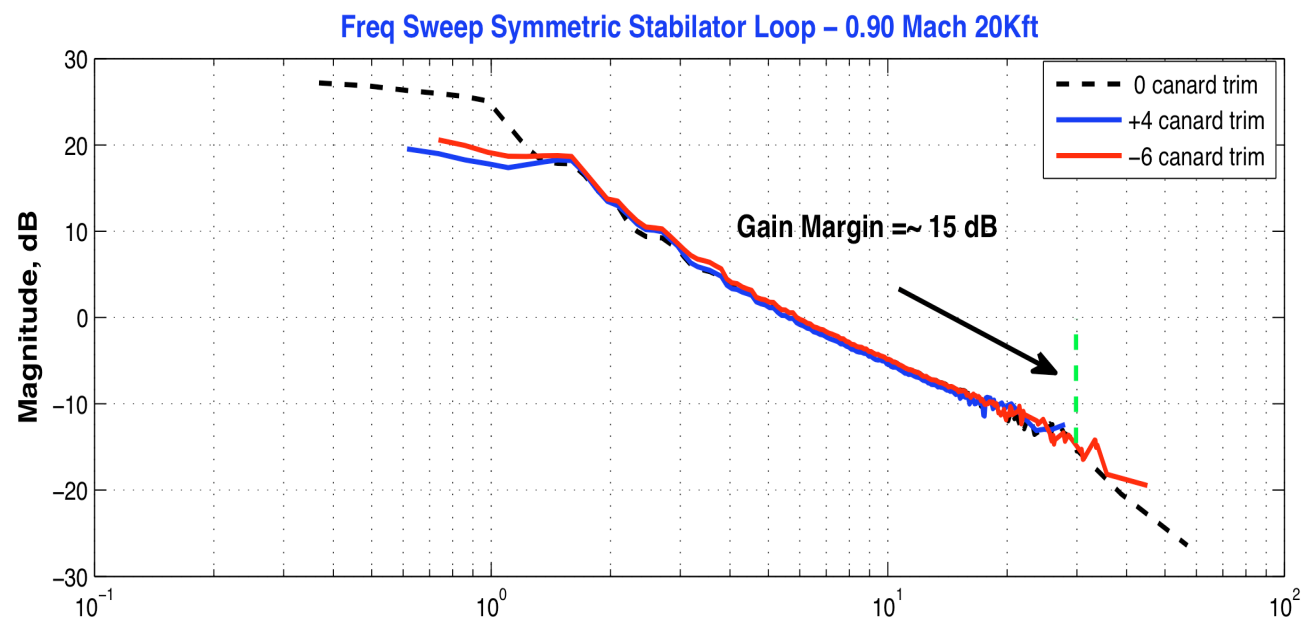

- Collective canards

- Collective rudders

- Differential stabilators

- Differential ailerons

- Lowest stability margins

- $\mathrm{GM}=8.8 \mathrm{~dB}$

- $P M=61.4^{\circ}$

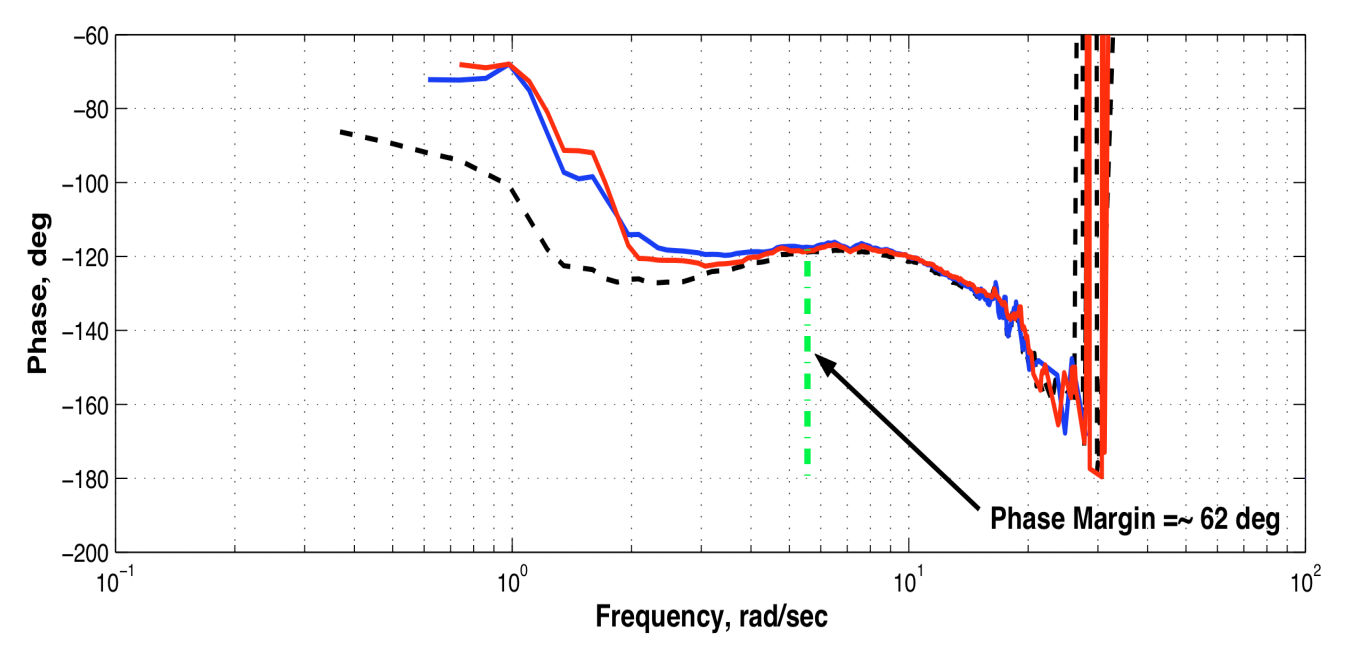




\section{Simulation Engage/Disengage Transient Analysis}

- No engagement transient issue

- Disengage Transient

- 3 canard trim biases $\left(0^{\circ},+3.3^{\circ},-5.4^{\circ}\right)$

- 4 disengagements methods

- NWS switch

- Paddle switch

- Trigger switch

- Enhanced switch

- Worst case transient - 1.85 g excursion

- Unexpected pitch nozzle transient

Simulated NWS Disengagement

Canard Trim Bias of $\mathbf{- 5 . 4}$ deg 0.9Mach 20Kft

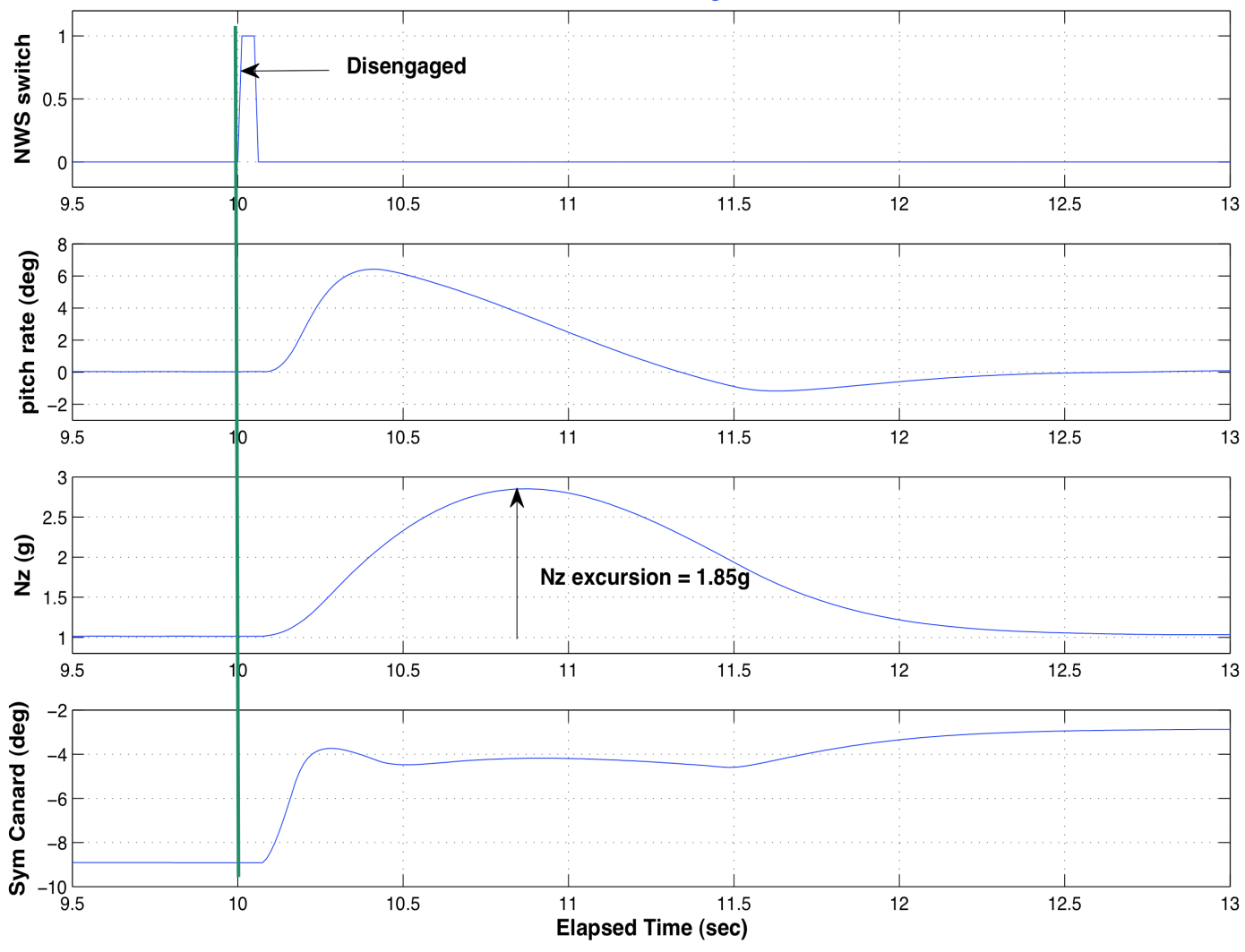




\section{Simulation Disengage Transient Analysis}

- Unexpected pitch nozzle transient with trigger switch

- Not observed nor documented as an issue during ILTV

- Question validity of LaNCETS sim

- Real or artifact of sim??

- Extensive search, review, and analysis of ILTV flight data confirmed pitch nozzle transient

- Lessons Learned

- Do not assume that if a problem was not reported during a flight test program that the problem does not exist

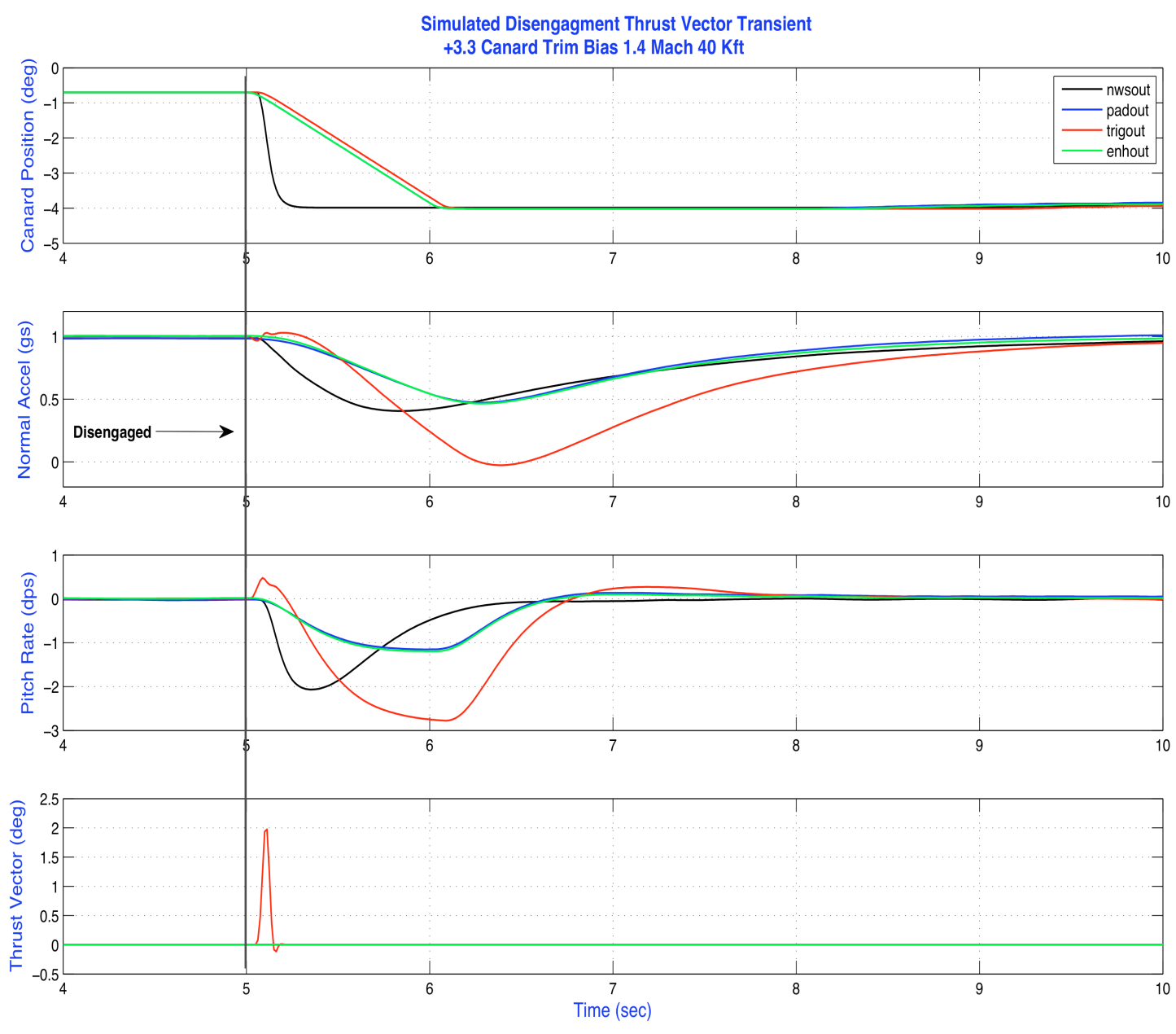

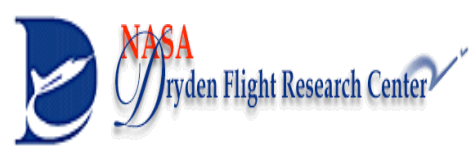




\section{Flight Test}

- Build up approach

- Piloted simulation evaluation was performed at worst case for aircraft dynamic responses and engagementdisengagement transients

- Dataset checkout and flight envelope clearance performed in subsonic flight regime prior to proceeding to supersonic flight regime

- ITB Clearance

- ITB, Dataset Clearance

- ASE Clearance

- Shock wave probing

- Canard trim biases

- $1.2 \mathrm{M} 40 \mathrm{Kft}, 1.4 \mathrm{M} 40 \mathrm{Kft}, 1.6 \mathrm{M}$ $40 \mathrm{Kft}, 1.4 \mathrm{M} 48 \mathrm{Kft}$

- Thrust vector biases

- $1.2 \mathrm{M} 40 \mathrm{Kft}, 1.4 \mathrm{M} 40 \mathrm{Kft}$

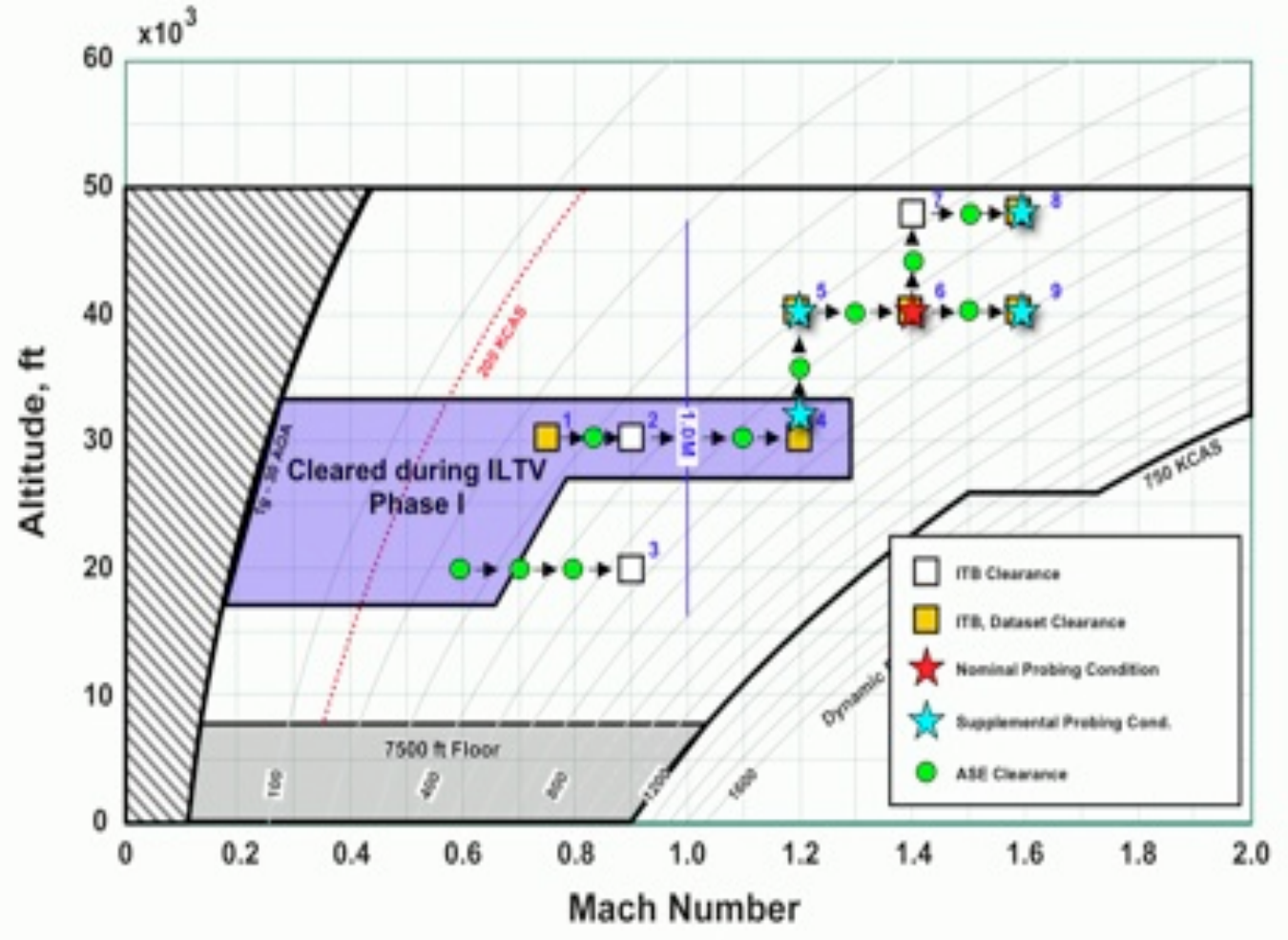




\section{Flight to Simulation Comparison}

- Simulation analysis tool validated with flight data

- Aircraft dynamic response to doublets were well damped
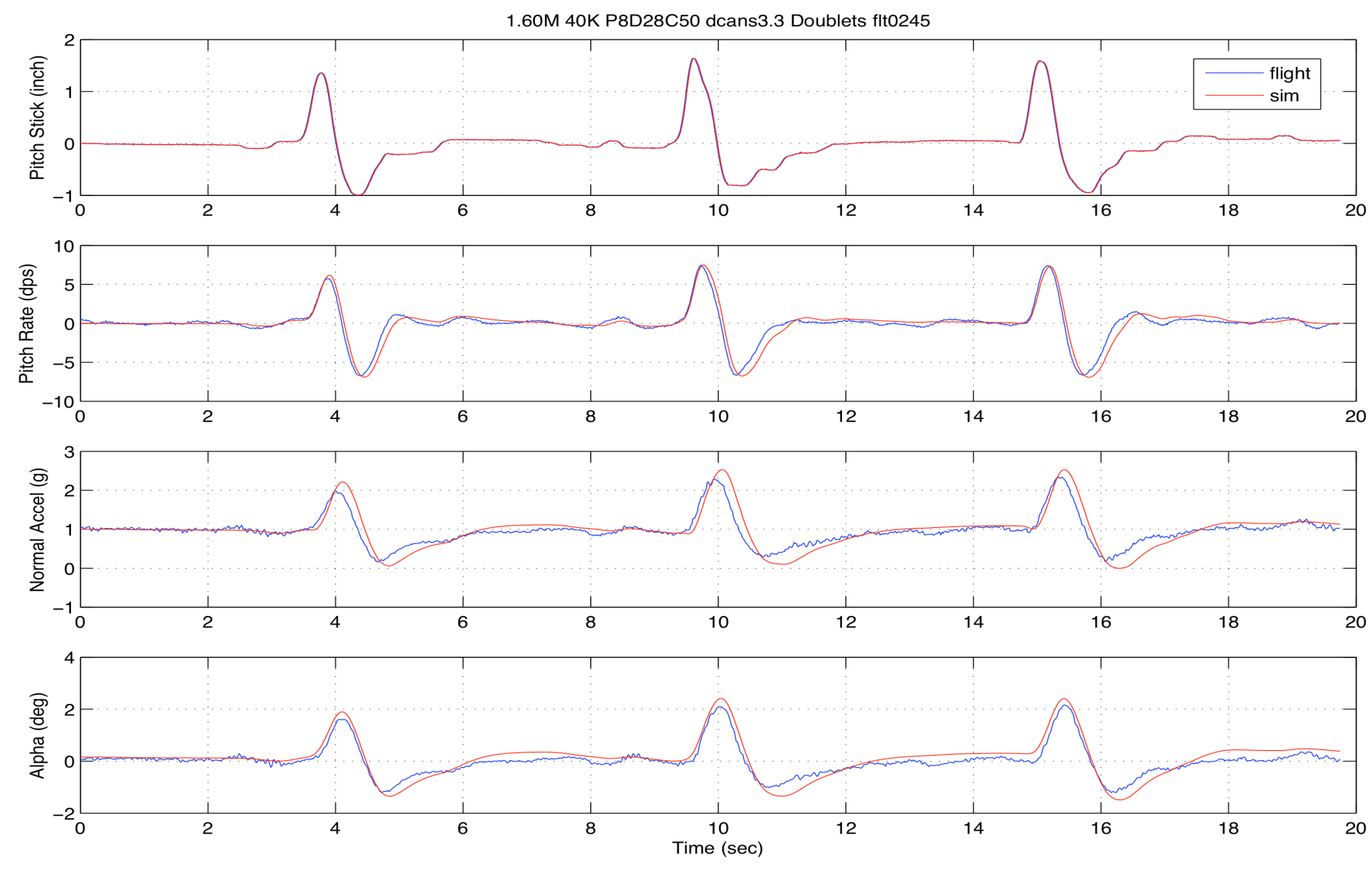


\section{Flight to Simulation Comparison}

- Disengagement transient comparisons were adequate

- Sim consistently overpredicts $\mathrm{N}_{\mathrm{z}}$ by as much as $0.7 \mathrm{~g}$

Flight to Sim Disengagement Transient Comparison

3.3 deg canard trim bias 1.4 Mach 40Kft

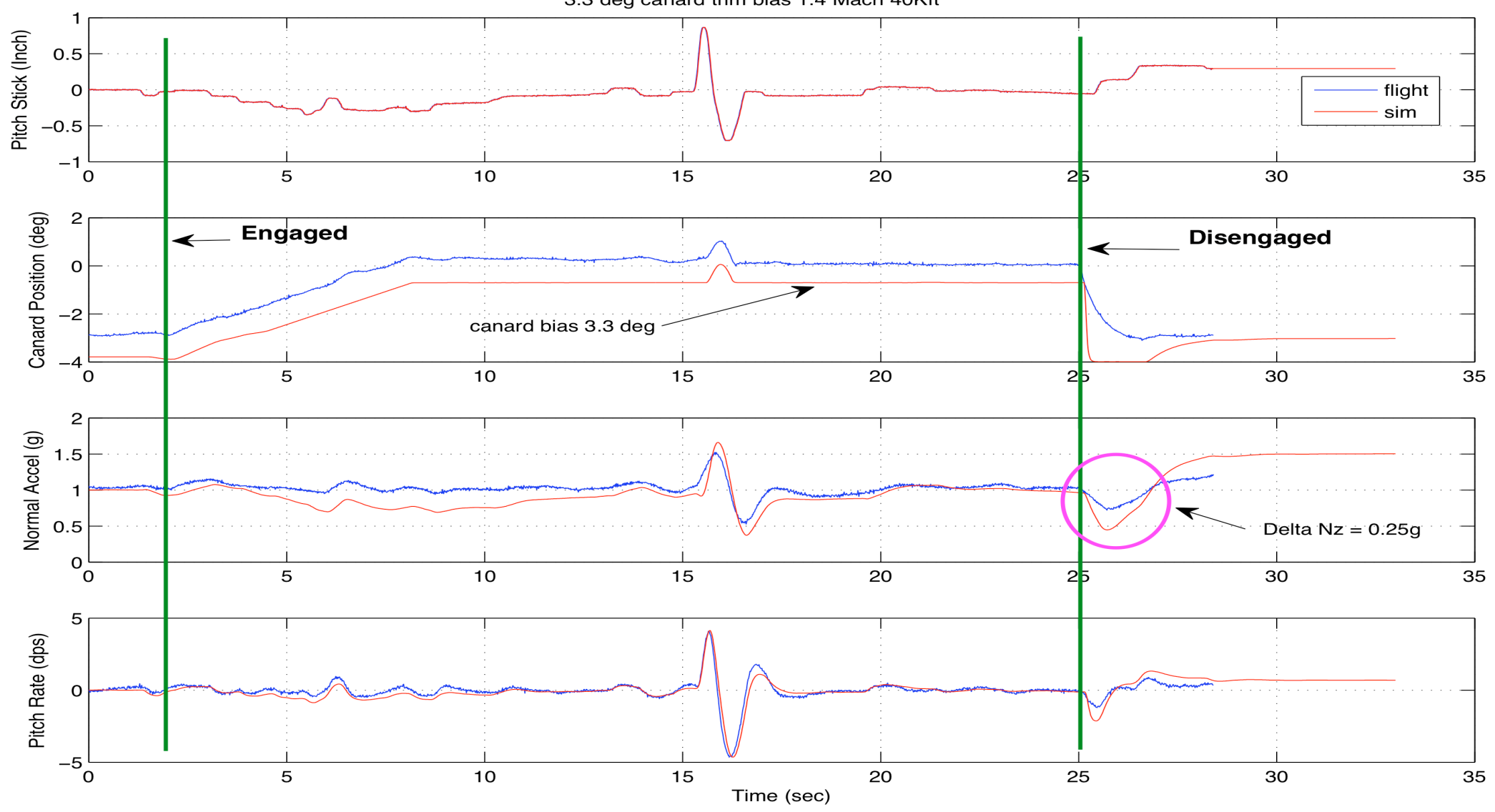




\section{Sampling Probing Result}

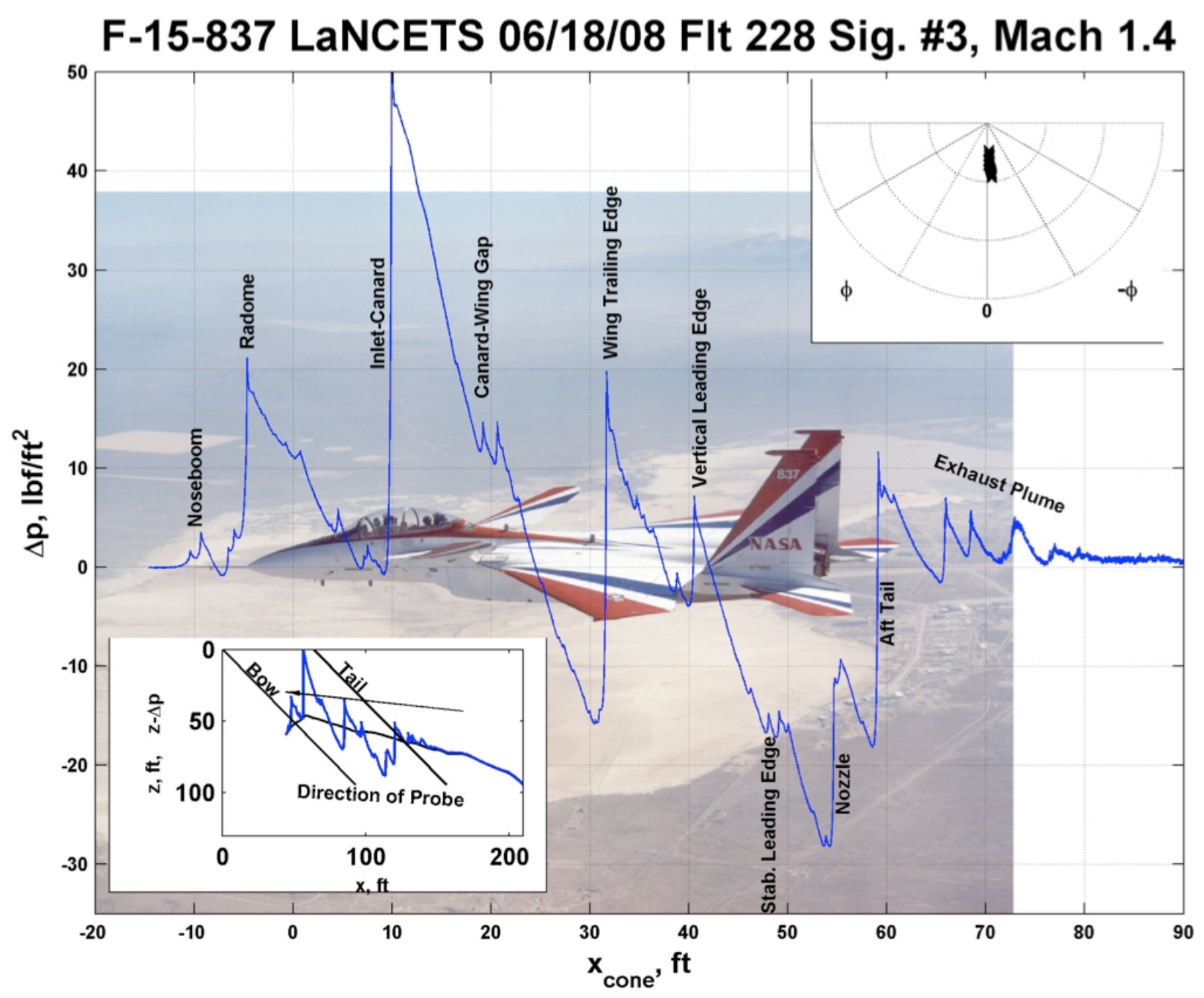

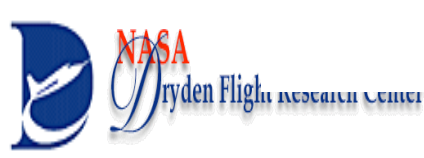




\section{Conclusion and Lessons Learned}

- Challenges encountered and lessons learned from resurrecting legacy ILTV flight controller

- Sim VnV

- Loss of corporate knowledge of legacy flight controller and simulation architecture

- Expand flight envelope

- Lessons Learned

- Document Document Document

- Store formal documents in archival system for easy retrieval of info

- Keep it simple for timely completion

- Do not assume that if a problem was not reported during a flight test program that the problem does not exist

- Shock wave probing were successfully completed 